\title{
CARTEL FORMATION WITH QUALITY DIFFERENTIATION
}

\author{
IWAN BOS, MARCO MARINI, AND RICCARDO SAULLE
}

\begin{abstract}
Research on collusion in vertically differentiated markets is conducted under one or two potentially restrictive assumptions. Either there is a single industry-wide cartel or costs are assumed to be independent of quality or quantity. We explore the extent to which these assumptions are indeed restrictive by relaxing both. For a wide range of coalition structures, profit-maximizing cartels of any size price most of their lower quality products out of the market as long as production costs do not increase too much with quality. If these costs rise sufficiently, however, then market share is maintained for all product variants. All cartel sizes may emerge in equilibrium when exclusively considering individual deviations, but the industry-wide cartel is the only one immune to deviations by coalitions of members. Overall, our findings suggest that firms have a strong incentive to coordinate prices when the products involved are vertically differentiated.
\end{abstract}

Keywords: Cartel Formation, Collusion, Vertical Differentiation, Endogenous Coalition Formation, Industry-wide Cartel, Partial Cartels.

JEL Classification: D42, D43, L1, L12, L13, L41.

\section{INTRODUCTION}

Two equally-priced products, A and B, are said to be vertically (or quality) differentiated when all buyers prefer A to B or vice versa. Quality differences, whether perceived or actual, typically allow those producing superior quality to charge more for their product or service. This has several strategic implications in terms of pricing and quality variations offered. For example, Mussa and Rosen (1978) establish that a monopolist prefers to sell lower quality goods at higher prices when compared to a competitive market. Similar analyses have been conducted for monopolistically competitive and duopolistic markets by Shaked and Sutton (1982) and Champsaur and Rochet (1989), respectively.

A more contemporary body of work explores the presence of quality heterogeneity in relation to price collusion. ${ }^{1}$ Häckner (1994), for instance, considers an infinitely repeated duopoly version of the vertical differentiation model in Gabszewicz and Thisse (1979) and Shaked and Sutton (1982). Among other things, he finds that the high quality supplier

Date: December 2019.

We greatly appreciate the comments of the editor and of two anonymous referees. All opinions and errors are ours alone.

Iwan Bos, Department of Organization Strategy \& Entrepreneurship, School of Business and Economics, Maastricht University. E-mail: i.bos@maastrichtuniversity.nl.

Marco A. Marini, Department of Social and Economic Sciences, Sapienza University of Rome and CREI. E-mail: marco.marini@uniroma1.it.

Riccardo D. Saulle, DSEA, University of Padova. E-mail: riccardo.saulle@.unipd.it.

${ }^{1} \mathrm{~A}$ detailed discussion of this literature is provided by Marini (2018). 
has the strongest incentive to chisel on the agreement. Within a representative consumer framework with horizontal and vertical product differentiation, Symeonidis (1999) draws the opposite conclusion; that is, it is the low quality supplier who is most eager to defect. Recently, Bos and Marini (2019) have shown that the contrasting conclusions of Häckner (1994) and Symeonidis (1999) critically depend on the price-cost margin of cartel members. Specifically, they establish a negative relationship between the collusive price-cost margin and the incentive to deviate from a price-fixing agreement.

All this and related analyses are performed under one or two potentially restrictive assumptions, however. Either production costs are taken to be identical (or even absent) or the cartel is assumed all-inclusive, i.e., each industry member takes part in the anticompetitive coalition. As to the first, producing higher quality products often requires more costly inputs. In many cases, therefore, it would be more natural to assume that production costs are increasing with both quality and quantity. ${ }^{2}$ Regarding the second, many discovered cartels have been less than all-inclusive in the sense that they faced competition from at least one firm not participating in the agreement. In the French yogurt cartel, for example, eleven firms fixed prices of supermarket own-brand yogurt from 2006 to 2012. Yet, the premium producer Danone did not take part in the conspiracy. ${ }^{3}$ For the year 2013, there is evidence of price collusion between two premium ice cream brands: Ben \& Jerry's and Häagen-Dazs. ${ }^{4}$ As yet another example, the global Vitamin $C$ and Citric Acid cartels from the 1990s excluded Chinese competitors. ${ }^{5}$

In this paper, our goal is to explore the extent to which these two assumptions are indeed restrictive. Towards that end, we study a modified version of the model in Mussa and Rosen (1978). Specifically, we adapt that setting to allow for oligopolistic price competition. Each firm is assumed to produce a unique quality variant at constant unit costs, which are increasing with quality. Within this framework, we examine properties of optimal pricefixing contracts and, in particular, how these depend on costs and the inclusiveness of the cartel. We furthermore analyze what coalitions are likely to form by endogenizing the cartel formation process.

Let us summarize some of our main findings. In line with the existing literature, a profitmaximizing all-inclusive cartel prefers to exclusively sell the highest quality product when unit costs increase weakly less than proportionally with quality. If costs increase more than proportionally, however, the optimal cartel contract stipulates positive sales for all product variants. A similar result holds for less than all-inclusive cartels. That is, if unit costs are not rising too much with quality, then colluders prefer to boost sales of their top quality product by pricing lower quality variants out of the market. Yet, when a cartel faces competition from an outsider offering inferior quality, it additionally chooses to produce the lowest quality available within the coalition (i.e., a so-called fighting brand). When unit costs increase more

\footnotetext{
${ }^{2}$ Some contributions, such as Gabszewicz, Marini and Tarola (2019), assume costs to depend on quality only and not on the quantity produced. That disregarding production costs may not be innocuous has been recently illustrated by Bos and Marini (2019). The only other work we are aware of that studies collusion while assuming costs to be increasing with quantity and quality is Ecchia and Lambertini (1997). That paper considers a vertically differentiated duopoly to study the impact of minimum quality standards on price collusion. Among other things, the authors establish that this standard makes price collusion more difficult provided that consumers' marginal willingness to pay for quality is sufficiently high.

${ }^{3}$ See Bonnet and Bouamra-Mechemache (2019).

${ }^{4}$ See Sullivan (2017) for a detailed analysis.

${ }^{5}$ See Bos (2009) and Bos and Harrington (2010), which contain many other examples of partial cartels.
} 
than proportionally with quality, the outcome is comparable to that under full collusion; all variants remain on sale.

Regarding the composition of cartels, we consider two coalition formation procedures which we coin the aggregative and the unanimity rule. These rules differ in terms of whether the coalition breaks down in the event of deviations. Under the aggregative rule, the remaining coalition structure stays unaffected by a defecting firm. By contrast, a deviating seller triggers a collapse into singletons under the unanimity rule. Studying these two polar cases is useful in settings like ours where coalition externalities are positive and monotonic, because it allows to predict the outcome for any non-deviating firm partition. ${ }^{6}$ We consider both individual and coalitional stability, i.e., whether coalition structures are immune to deviations by individual or subgroups of members.

Assuming constant differences between adjacent qualities and associated costs, we find that any coalition structure can be individually stable under both the aggregative and the unanimity rule. Yet, with the possible exception of the grand coalition, none of them is coalitionally stable. Additional numerical analyses suggest that the all-inclusive cartel can also be stable when costs are increasing more or less than proportionally with quality. In terms of policy implications, these findings suggest that firms have a fairly strong incentive to collude when the products involved are vertically differentiated. In particular, an industrywide price increase in conjunction with a decrease of the number of quality variants offered should be considered a tell-tale sign of collusion. ${ }^{7}$

Since each seller has a unique market position within our setting, this paper is related to literature about cartel formation with heterogeneous firms. Donsimoni (1985), for instance, considers a collusive price leadership model with different unit costs. She establishes the existence of a stable partial cartel comprising the most efficient industry members. In a related fashion, Bos and Harrington (2010) show that there is a positive relation between firm size and the incentive to join a cartel. ${ }^{8}$ Recently, Merker (2019) suggests that the size of partial cartels may be inversely related to the degree of horizontal product differentiation. The only other work we are aware of that combines coalition formation with quality differentiation is Gabszewicz, Marini and Tarola (2019). In a three-firm market, and under the assumption that costs depend exclusively on quality, they establish that the grand coalition does not emerge in equilibrium.

The next section introduces the model. Section 3 discusses the noncollusive solution. Section 4 presents properties of an optimal price-fixing contract under full and partial collusion, respectively. Endogenous cartel formation is considered in Section 5. Section 6 concludes. All proofs are relegated to the Appendix.

\footnotetext{
${ }^{6}$ Another body of work analyzes the stability of coalition structures absent externalities across coalitions (see, e.g., Farrell and Scotchmer (1988), Demange (1994)). This literature typically assumes coalitions to be hedonic and players' payoffs to depend exclusively on the size of their own coalition (see, e.g., Drèze and Greenberg, (1980)). For an extensive overview of this research, see the recent survey by Demange (2017).

${ }^{7}$ In this paper, we focus on price cartels in the presence of quality heterogeneity. In principle, many of our findings may also be applicable to mergers and acquisitions. Note, however, that from a policy perspective this would require the possibility of cost synergies; something that is excluded in the ensuing analysis.

${ }^{8}$ This is confirmed by Paha (2010). Yet, he also argues that larger firms may show less eagerness to collude in order to mitigate free-riding incentives by smaller rivals.
} 


\section{MODEL}

There is a given set of $n$ profit-maximizing firms, $N=\{1, \ldots, n\}$, that simultaneously pick prices. Each firm $i \in N$ offers a product variant $v_{i}$, which vary in terms of (perceived) quality. In particular, it is assumed that:

$$
\infty>v_{n}>v_{n-1}>\ldots>v_{1}>0 .
$$

Variable production $\operatorname{costs} c_{i}$ are constant per unit of output and weakly positively related to quality: $c_{n} \geq c_{n-1} \geq \ldots \geq c_{1}>0$. All fixed costs are sunk.

Demand comes from a unit mass of utility-maximizing consumers who are uniformly distributed on $[0, \bar{\theta}] \subset \mathcal{R}_{+}$(with $\bar{\theta}>0$ ). Specifically, consumers' willingness to pay for quality is given by $\theta \in[0, \bar{\theta}]$ and those with a higher $\theta$ attach more value to quality. Each of the customers chooses between buying one unit of the product and not buying in which case (s)he obtains zero utility. Consequently, consumers 'located' at $\theta$ face the following utility specification:

$$
U(\theta)=\left\{\begin{array}{c}
\theta v_{i}-p_{i} \text { when buying variant } i \\
0 \text { when not buying, }
\end{array}\right.
$$

where $p_{i} \in\left[0, \bar{\theta} v_{n}\right]$ is the price charged by firm $i \in N .{ }^{9}$ We further assume that $\bar{\theta}\left(v_{n}-v_{n-1}\right)>$ $c_{n}-c_{n-1}$, which ensures that there is scope for the highest quality product by putting an upper bound on its production costs.

Before proceeding, let us make two observations. First, note that there is a positive mass of consumers who prefer not to buy a product when prices are strictly positive. ${ }^{10}$ As will become clear in the ensuing analysis, this has the implication that the market is uncovered ex ante. ${ }^{11}$ Second, to have demand for each product variant requires superior qualities to be offered at a higher price.

To further specify a firm's demand, consider a consumer at $\theta \in[0, \bar{\theta}]$. This consumer is indifferent between buying from firm $i+1$ and $i$ when:

$$
\theta v_{i+1}-p_{i+1}=\theta v_{i}-p_{i} \Longrightarrow \theta_{i}\left(p_{i}, p_{i+1}\right)=\frac{p_{i+1}-p_{i}}{v_{i+1}-v_{i}}
$$

for $i=1,2, \ldots, n-1$. Similarly, a consumer at $\theta \in[0, \bar{\theta}]$ is indifferent between buying variant $v_{1}$ and buying nothing when

$$
\theta v_{1}-p_{1}=0 \Longrightarrow \theta_{0}\left(p_{1}\right)=\frac{p_{1}}{v_{1}} .
$$

We can now distinguish three types of profit functions. The profit function of the firm offering the lowest quality (firm 1) is given by:

$$
\Pi_{1}\left(p_{1}, p_{2}\right)=\left(p_{1}-c_{1}\right) \cdot\left(\frac{p_{2}-p_{1}}{v_{2}-v_{1}}-\frac{p_{1}}{v_{1}}\right)
$$

\footnotetext{
${ }^{9}$ Notice that none of the buyers would buy a product at a price in excess of $\bar{\theta} v_{n}$.

${ }^{10}$ To illustrate, if $p_{i}>0, \forall i \in N$, then $U(\theta=0)=0 \cdot v_{i}-p_{i}<0$. Thus, $\exists \widetilde{\theta}>0$ such that all consumers with $\theta<\widetilde{\theta}$ prefer not to buy the product.

${ }^{11}$ This also implies that the market remains uncovered throughout our analysis since collusive prices are higher than their noncollusive counterparts.
} 
Payoffs of firms producing an intermediate quality variant $(i=2,3, \ldots, n-1)$ take the following form

$$
\Pi_{i}\left(p_{i-1}, p_{i}, p_{i+1}\right)=\left(p_{i}-c_{i}\right) \cdot\left(\frac{p_{i+1}-p_{i}}{v_{i+1}-v_{i}}-\frac{p_{i}-p_{i-1}}{v_{i}-v_{i-1}}\right) .
$$

Finally, the profit function of the top quality firm (firm $n$ ) is

$$
\Pi_{n}\left(p_{n-1}, p_{n}\right)=\left(p_{n}-c_{n}\right) \cdot\left(\bar{\theta}-\frac{p_{n}-p_{n-1}}{v_{n}-v_{n-1}}\right) .
$$

\section{Nash Price Equilibrium}

We now consider some properties of the profit functions (2.2)-(2.4) and establish conditions for the existence of an interior Nash price equilibrium. As a first observation, it can be easily verified that each profit function is strictly concave in the own price and has a unique maximum given rivals' prices. This has the implication that firms' best-responses are functions rather than correspondences.

Let us derive these best-response functions. Taking the first-order conditions and rearranging gives the best-reply functions for the lowest quality seller (firm 1),

$$
p_{1}\left(p_{2}\right)=\frac{v_{1}}{2 v_{2}} \cdot p_{2}+\frac{1}{2} c_{1}
$$

for every intermediate quality supplier $(i=2,3, \ldots, n-1)$,

$$
p_{i}\left(p_{i-1}, p_{+1}\right)=\frac{\left(v_{i+1}-v_{i}\right) \cdot p_{i-1}+\left(v_{i}-v_{i-1}\right) \cdot p_{i+1}}{2\left(v_{i+1}-v_{i-1}\right)}+\frac{1}{2} c_{i},
$$

and, finally, for the top quality producer (firm $n$ ),

$$
p_{n}\left(p_{n-1}\right)=\frac{1}{2}\left(p_{n-1}+\bar{\theta}\left(v_{n}-v_{n-1}\right)\right)+\frac{1}{2} c_{n} .
$$

Observe that each best-response price is increasing in the price of an adjacent quality variant as well as in the own unit production costs. Moreover, a firm's own price is a strategic complement with respect to its own quality $\left(\frac{\partial_{i}^{2} \Pi_{i}}{\partial p_{i} \partial v_{i}}>0\right)$, whereas it is a strategic substitute with respect to adjacent rivaling qualities $\left(\frac{\partial_{i}^{2} \Pi_{i}}{\partial p_{i} \partial v_{j}}<0, j=i-1, i+1\right)$. A firm's best-response curve thus shifts upward when its own quality increases and downward when the quality of a direct rival increases. This is because the former relaxes price competition, whereas the latter intensifies it, all else unchanged.

Notice further that, since firms' strategic choice sets are compact as well as convex and their best-responses are contractions, there exists a unique Nash equilibrium price vector $p^{*}$ for any finite number of firms. ${ }^{12}$ The following two conditions are sufficient to ensure that

\footnotetext{
${ }^{12}$ See, for instance, Friedman (1991, p.84). A sufficient condition for the contraction property to hold is (see, for example, Vives 2000, p.47):

$$
\frac{\partial^{2} \Pi_{i}}{\partial p_{i}^{2}}+\sum_{j \neq i}\left|\frac{\partial^{2} \Pi_{i}}{\partial p_{i} \partial p_{j}}\right|<0
$$
}

which, using (2.3) for all intermediate firms $i=2, \ldots, n-1$, becomes

$$
\frac{v_{i-1}-v_{i+1}}{\left(v_{i+1}-v_{i}\right) \cdot\left(v_{i}-v_{i-1}\right)}<0
$$


this Nash equilibrium solution is interior (i.e., all firms are productive at $\left.p^{*}\right)$ :

$$
\bar{\theta}>\theta_{n-1}^{*}>\theta_{n-2}^{*}>\ldots>\theta_{i}^{*}>\ldots>\theta_{1}^{*}>\theta_{0}^{*}>0,
$$

where $\theta_{i}^{*} \equiv \theta_{i}\left(p_{i}^{*}, p_{i+1}^{*}\right)$ and $p_{i}^{*} \geq c_{i}$, for all $i \in N$. Roughly speaking, the first condition states that all firms have positive demand in equilibrium, whereas the second guarantees that each firm finds it profitable to meet this demand.

\section{Optimal Price Collusion}

Let us now direct our attention to the possibility that firms coordinate their pricing decisions. In the following, we explore the traits of an optimal price-fixing agreement under the assumption that cartel members aim to maximize total cartel profits. We distinguish between the industry-wide and less than industry-wide cartels. For the sake of simplicity, we abstain from issues related to the sustainability of collusive agreements. ${ }^{13}$

4.1. Full Collusion. Under full collusion, each firm sets its price to maximize total industry profit $\Pi_{N}^{(\{N\})}$ :

$$
\max _{\left(p_{1}, p_{2}, \ldots, p_{n}\right)} \Pi_{N}^{(\{N\})}=\Pi_{1}+\ldots+\Pi_{i-1}+\Pi_{i}+\Pi_{i+1}+\ldots+\Pi_{n}
$$

Thus, the following first-order condition must hold for each firm $i \in N:{ }^{14}$

$$
\frac{\partial \Pi_{N}^{\{N\}}}{\partial p_{i}}=\frac{\partial \Pi_{i-1}}{\partial p_{i}}+\frac{\partial \Pi_{i}}{\partial p_{i}}+\frac{\partial \Pi_{i+1}}{\partial p_{i}}=0 .
$$

The collusive best-response of the lowest quality supplier (firm 1) is then

$$
p_{1}^{c}\left(p_{2}\right)=\frac{v_{1}}{2 v_{2}} \cdot\left(2 p_{2}-c_{2}\right)+\frac{1}{2} c_{1},
$$

where the superscript ' $c$ ' indicates collusion. For all intermediate quality firms $(i=2,3, \ldots, n-$ 1), the optimal collusive price is given by

$$
p_{i}^{c}\left(p_{i-1}, p_{i+1}\right)=\frac{\left(v_{i+1}-v_{i}\right) \cdot\left(2 p_{i-1}-c_{i-1}\right)+\left(v_{i}-v_{i-1}\right) \cdot\left(2 p_{i+1}-c_{i+1}\right)}{2\left(v_{i+1}-v_{i-1}\right)}+\frac{1}{2} c_{i} .
$$

Finally, the collusive best-reply of the top quality firm (firm $n$ ) is

$$
p_{n}^{c}\left(p_{n-1}\right)=\frac{1}{2}\left(2 p_{n-1}-c_{n-1}+\bar{\theta}\left(v_{n}-v_{n-1}\right)\right)+\frac{1}{2} c_{n}
$$

which holds. The same applies for firm 1 and firm $n$.

${ }^{13}$ Akin to Bos and Marini (2019), our results could be derived within the context of an infinitely repeated price game. In such a setting, the profit-maximizing cartel agreements are sustainable through standard means when members have a suffciently high discount factor.

${ }^{14}$ Note that $\frac{\left.\partial^{2} \Pi_{N}\right\}}{\partial p_{i}^{2}}=-\frac{2\left(v_{i+1}-v_{i-1}\right)}{\left(v_{i+1}-v_{i}\right) \cdot\left(v_{i}-v_{i-1}\right)}<0$ for $i=2,3, \ldots, n-1$, and, therefore, the joint profit $\left.\Pi^{\{N}\right\}$ is concave in every firm's price $p_{i}$. A similar condition holds for the two firms selling the two extreme variants along the quality spectrum, namely firm 1 and firm $n$. 
Solving this system of $n$ first-order conditions (4.2)-(4.4) yields the following profit-maximizing collusive price vector $\mathbf{p}^{c}=\left(p_{1}^{c}, p_{2}^{c}, \ldots, p_{i}^{c}, \ldots, p_{n}^{c}\right)$ :

$$
\mathbf{p}^{c}=\left[\begin{array}{c}
p_{1}^{c} \\
p_{2}^{c} \\
\cdots \ldots \ldots \\
p_{i}^{c} \\
\cdots \ldots \ldots \\
p_{n}^{c}
\end{array}\right]=\left[\begin{array}{c}
\frac{1}{2}\left(\bar{\theta} v_{1}+c_{1}\right) \\
\frac{1}{2}\left(\bar{\theta} v_{2}+c_{2}\right) \\
\ldots \ldots \ldots \\
\frac{1}{2}\left(\bar{\theta} v_{i}+c_{i}\right) \\
\ldots \ldots \ldots \\
\frac{1}{2}\left(\bar{\theta} v_{n}+c_{n}\right)
\end{array}\right] .
$$

In turn, this determines the optimal allocation of output across cartel members, which is specified in the following proposition. In stating this result, let the demand for the products of an individual cartel member under full collusion be given by $D_{i}^{c}, i \in N$.

Proposition 1. Assume full collusion. Total cartel demand is allocated as follows:

$$
\mathbf{D}^{c}=\left[\begin{array}{c}
D_{1}^{c} \\
D_{2}^{c} \\
\cdots \ldots \ldots \\
D_{i}^{c} \\
\cdots \ldots \ldots \\
D_{n}^{c}
\end{array}\right]=\left[\begin{array}{c}
\frac{1}{2}\left(\frac{c_{2}-c_{1}}{v_{2}-v_{1}}-\frac{c_{1}}{v_{1}}\right) \\
\frac{1}{2}\left(\frac{c_{3}-c_{2}}{v_{3}-v_{2}}-\frac{c_{2}-c_{1}}{v_{2}-v_{1}}\right) \\
\ldots \ldots \ldots \\
\frac{1}{2}\left(\begin{array}{c}
c_{i+1}-c_{i} \\
v_{i+1}-v_{i}
\end{array}-\frac{c_{i}-c_{i-1}}{v_{i}-v_{i-1}}\right) \\
\ldots \ldots \ldots \\
\frac{1}{2}\left(\bar{\theta}-\frac{c_{n}-c_{n-1}}{v_{n}-v_{n-1}}\right)
\end{array}\right] .
$$

Observe that the allocation of collusive output depends critically on the unit production costs and, in particular, the degree to which costs are increasing with quality. The next result follows immediately.

Corollary 1. Assume full collusion. (i) If costs increase weakly less than proportionally with quality, then $D_{n}^{c}>0$ and $D_{i}^{c}=0$, for all $i \in N \backslash\{n\}$. (ii) If costs increase more than proportionally with quality, then $D_{i}^{c}>0$, for all $i \in N$.

Part $(i)$ is reminiscent of a well-known result in the classic literature on multi-product monopoly with quality differentiation. Indeed, Mussa and Rosen (1978) show that a monopolist may find it optimal to supply lower qualities at higher prices to boost revenues from its upper-end products. Offering sufficiently unattractive lower quality products allows to extract more consumer surplus from those who have a high willingness to pay for quality.

Although price is the only choice variable in our setting, the all-inclusive cartel effectively operates as a multi-plant monopolist and the forces at work are the same. Indeed, for a given range of product variants, part $(i)$ shows that an industry-wide cartel prefers to sell exclusively to those who value quality a lot provided that production costs are not increasing too much with quality. However, as part (ii) indicates, such a pricing strategy is no longer optimal when production costs increase more than proportionally with quality. If the profit margin on the highest-quality products is too limited, then it is more profitable to set collusive prices in such a way that all variants remain on sale. 
4.2. Partial Collusion. We now consider the possibility that only subsets of firms coordinate their prices. Our focus is on consecutive coalitions that may face a competitive fringe of independent sellers or other partial cartels. There are therefore three types of price agreement: (1) a partial cartel including the highest quality firm (top quality cartel), (2) a partial cartel including the lowest quality firm (bottom quality cartel) and (3) a partial cartel including intermediate quality firms only (intermediate quality cartel).

As before, let us start by deriving the collusive best-replies. Since the coalitions under consideration are less than all-inclusive, we can distinguish between members with two adjacent firms that also participate in the cartel (interior cartel members) and members with only one adjacent cartel participant (boundary cartel members).

Now consider some partial coalition $S \subset N$. Akin to the all-inclusive cartel case, the collusive best-response of interior members is given by the following first-order condition:

or

$$
\frac{\partial \sum_{i \in S} \Pi_{i}}{\partial p_{i}}=\frac{\partial \Pi_{i-1}}{\partial p_{i}}+\frac{\partial \Pi_{i}}{\partial p_{i}}+\frac{\partial \Pi_{i+1}}{\partial p_{i}}=0
$$

$$
p_{i}^{p}\left(p_{i-1}^{p}, p_{i+1}^{p}\right)=\frac{\left(v_{i}-v_{i-1}\right) \cdot\left(2 p_{i+1}^{p}-c_{i+1}\right)+\left(v_{i+1}-v_{i}\right) \cdot\left(2 p_{i-1}^{p}-c_{i-1}\right)}{2\left(v_{i+1}-v_{i-1}\right)}+\frac{1}{2} c_{i},
$$

where the superscript ' $\mathrm{p}$ ' indicates membership of the partial cartel under consideration.

Next, consider the case of a boundary cartel member facing direct competition from an adjacent outsider that offers a superior quality. The collusive best-reply of this firm is implied by the following first-order condition:

or

$$
\frac{\partial \sum_{i \in S} \Pi_{i}}{\partial p_{i}}=\frac{\partial \Pi_{i}}{\partial p_{i}}+\frac{\partial \Pi_{i-1}}{\partial p_{i}}=0
$$

$$
p_{i}^{p}\left(p_{i-1}^{p}, p_{i+1}\right)=\frac{\left(v_{i}-v_{i-1}\right) \cdot p_{i+1}+\left(v_{i+1}-v_{i}\right) \cdot\left(2 p_{i-1}^{p}-c_{i-1}\right)}{2\left(v_{i+1}-v_{i-1}\right)}+\frac{1}{2} c_{i} .
$$

Finally, top and intermediate quality cartels have a boundary member that faces direct competition from an inferior quality outsider. The collusive best-reply of such a boundary member is given by:

or

$$
\frac{\partial \sum_{i \in S} \Pi_{i}}{\partial p_{i}}=\frac{\partial \Pi_{i}}{\partial p_{i}}+\frac{\partial \Pi_{i+1}}{\partial p_{i}}=0
$$

$$
p_{i}^{p}\left(p_{i-1}, p_{i+1}^{p}\right)=\frac{\left(v_{i}-v_{i-1}\right) \cdot\left(2 p_{i+1}^{p}-c_{i+1}\right)+\left(v_{i+1}-v_{i}\right) \cdot p_{i-1}}{2\left(v_{i+1}-v_{i-1}\right)}+\frac{1}{2} c_{i} .
$$

The above collusive best-replies can be used to characterize the optimal design of less than all-inclusive price-fixing agreements. As the next proposition shows, a profit-maximizing partial cartel prices the products of each interior cartel member out of the market when costs increase less than proportionally with quality.

Proposition 2. Assume a joint-profit-maximizing partial cartel. If costs increase weakly less than proportionally with quality, then none of its interior members have sales. 
Akin to the all-encompassing cartel, a partial coalition can extract more consumer surplus by increasing sales of its highest quality product. Whether such quality upshifting is profitable depends on the additional costs of producing extra quality, however. If costs do not rise too much with quality, then partial cartels find it profitable to effectively make their interior members exit the industry.

The same does not necessarily hold for a lowest-quality boundary member. Assuming no production costs, Gabszewicz, Marini and Tarola (2017) have shown that both top and intermediate quality cartels may find it in their interest to keep their lowest-quality product on sale. The next finding shows that supplying such a fighting brand is indeed beneficial provided that it is not too costly to produce.

Proposition 3. Assume a joint-profit-maximizing top or intermediate quality cartel. If the production costs of a boundary member are sufficiently small, then it has strictly positive sales.

The fighting brand basically functions as a cushion by dampening the impact of competitive pricing by low-quality outsiders. Therefore, by adopting such a strategy, the cartel effectively protects the profit-margin on its high quality sales.

Finally, as the next result reveals, each partial cartel member maintains a positive market share when production costs increase more than proportionally with quality.

Proposition 4. Assume a joint-profit-maximizing partial cartel. If costs increase more than proportionally with quality, then all of its members have strictly positive sales.

This finding is directly comparable to Corollary (ii) above and the underlying logic is the same. That is, the quality upshifting incentive is mitigated by the additional costs of producing more quality. In this case, like with full collusion, partial cartels have their prices rise sufficiently with quality so that all variants remain on sale.

\section{Endogenous Coalition Formation}

In the previous section, results have been derived for a given coalition structure. Let us now turn to the issue of coalition formation. Specifically, our aim is to shed light on what cartels would emerge when the products involved are vertically differentiated. Towards that end, we add two ingredients to the preceding analysis: a coalition formation procedure and a notion of stability. The first describes how a cartel agreement can be established. The second specifies what cartel agreements are, in fact, viable. To keep the analysis tractable and focus on the impact of costs, we assume in the ensuing exploration that product variants are equispaced, i.e., $\left|v_{j}-v_{i}\right|=d$ for any adjacent pair of firms $i, j \in N, i \neq j$, and $v_{1}=d$.

Starting with the coalition formation procedure, we assume that each producer $i \in N$ simultaneously sends a proposal, $\rho_{i}=\left(S, \sigma_{S}\right)$, to all other firms. Here, $S \subseteq N$ is the coalition of connected firms to which it wants to belong and $\sigma_{S}=\left\{\sigma_{i}\right\}_{i \in S}$ is a corresponding sharing rule; a proposed distribution of joint cartel profits among prospective members with $\sum_{i \in S} \sigma_{i}=1$.

Each profile of proposals, $\rho=\left(\rho_{1}, \rho_{2}, \ldots, \rho_{n}\right)$, consequently induces a coalition structure, $C=\left(\left\{S_{1}\right\},\left\{S_{2}\right\}, \ldots,\left\{S_{m}\right\}\right)$, comprising $m \leq n$ coalitions. A key issue is then how exactly this process takes place. In the following, we consider two well-known coalition formation rules: 
the unanimity rule and the aggregative rule. ${ }^{15}$ According to the unanimity rule, a coalition is formed if and only if the prospective members propose precisely the same coalition with an associated sharing rule. Formally, the coalition structure

$$
C^{U}(\rho)=\left(\left\{S_{1}(\rho)\right\},\left\{S_{2}(\rho)\right\}, \ldots,\left\{S_{k}(\rho)\right\}, \ldots,\left\{S_{m}(\rho)\right\}\right),
$$

is such that firm $i$ takes part in $S_{k}(k=1,2, \ldots, m)$ if and only if $\rho_{i}=\left(S_{k}, \sigma_{S_{k}}\right)$, for all $i \in S_{k}$, and remains independent otherwise. According to the aggregative rule, a coalition forms if and only if its prospective members propose the same coalition (not necessarily one that actually forms) as well as the same sharing rule. Formally, the coalition structure

$$
C^{A}(\rho)=\left(\left\{S_{1}(\rho)\right\},\left\{S_{2}(\rho)\right\}, \ldots,\left\{S_{k}(\rho)\right\}, \ldots,\left\{S_{m}(\rho)\right\}\right),
$$

is such that firm $i$ belongs to $S_{k}(k=1,2, . ., m)$ if and only if $\rho_{i}=\rho_{j}$ for all $i, j \in S_{k}$ and remains a singleton otherwise.

The two coalition formation rules essentially differ in their response to deviations by one or more prospective members. Whereas the remaining firms split-up into singletons under the unanimity rule, they stick together under the aggregative rule. To illustrate, consider the following example. Suppose the industry comprises three firms, $i, j$, and $h$. Suppose further that firms $i$ and $j$ announce the all-inclusive cartel with an even allocation of collusive profits (i.e., $\left.\rho_{i}=\rho_{j}=(\{i, j, h\},(1 / 3,1 / 3,1 / 3))\right)$, whereas firm $h$ announces $\rho_{h}=(\{h\}, 1)$. The outcome under the unanimity rule is that all firms remain singletons: $C^{U}(\rho)=((\{i\},\{j\},\{h\}),(1,1,1))$. Under the aggregative rule, however, the same profile of proposals results in the coalition structure $C^{A}(\rho)=((\{i, j\},(1 / 2,1 / 2)),(\{h\},(1)))$ so that a partial cartel between firm $i$ and firm $j$ will emerge. Following this example, we assume in the following that when the aggregative rule applies, the proposed sharing rule will be effectively rescaled in accordance with the coalition that actually forms. ${ }^{16}$

Apart from their relative simplicity, these two coalition formation rules are also attractive in that they describe two polar cases regarding how to respond to deviations. In particular, this approach allows to predict the outcome for any non-deviating firm partition when coalition externalities are monotonic like in our setting.

Next, let us consider the viability of coalitions. To that end, we introduce two notions of stability; one in which only individual defections are permitted and another that allows for deviations by subcoalitions. Define

$$
\Pi_{i}(\rho) \equiv \sigma_{i} \Pi_{S_{k}}\left(\mathbf{p}^{*}(C(\rho))\right) \text { for all } i \in S_{k}, S_{k} \in C \text { and } \sigma_{i} \in \sigma_{S_{k}}
$$

as the payoff of a producer belonging to coalition $S_{k}$ under price equilibrium $\mathbf{p}^{*}$ when the coalition structure $C(\rho)=\left(\left\{S_{1}\right\},\left\{S_{2}\right\}, \ldots,\left\{S_{m}\right\}\right)$ is induced by a profile of proposals $\rho=$ $\left(\rho_{1}, \rho_{2}, \ldots, \rho_{n}\right)$.

We then have the following definitions for individual and coalitional stability, respectively.

\footnotetext{
${ }^{15}$ The unanimity rule was introduced formally by von Neumann and Morgenstern (1944) and later on coined the gamma-rule of coalition formation. The aggregative rule is also referred to as the delta-rule of coalition formation (see, e.g., Hart and Kurz (1983)).

${ }^{16}$ The re-scaled sharing rule, $r: \mathcal{R}_{+}^{S_{k}} \rightarrow \mathcal{R}_{+}^{S_{k}^{\prime}}$ (where $S_{k}^{\prime}$ indicates the coalition which ultimately forms) is $r=\left(r_{1}, r_{2}, \ldots, r_{S_{k}^{\prime}}\right)$, obtained by solving $\sum_{i \in S_{k}^{\prime}} r_{i}=1$, for $r_{i}=\alpha_{i} \sigma_{h}$, where $\alpha_{i}$ denotes the ratio between every proposed share $\sigma_{i}$ and one firm's share $\sigma_{h}\left(h \in S_{k}^{\prime}\right)$ used as numeraire.
} 
Definition 1 (Individual or Nash stability) Coalition structure $C=\left(\left\{S_{1}\right\},\left\{S_{2}\right\}, . .,\left\{S_{m}\right\}\right)$ is individually (or Nash) stable when $C=S\left(\rho^{*}\right)$ for some $\rho^{*}$ such that for every firm $i \in N$ and every alternative proposal $\rho_{i}^{\prime}$ it holds that

$$
\Pi_{i}\left(\rho^{*}\right) \geq \Pi_{i}\left(\rho_{i}^{\prime}, \rho_{N \backslash i}^{*}\right)
$$

Definition 2 (Coalitional or strong Nash stability) Coalition structure $C=\left(\left\{S_{1}\right\},\left\{S_{2}\right\}, . .,\left\{S_{m}\right\}\right)$ is coalitionally (or strong Nash) stable when $C=C(\widehat{\rho})$ for some $\widehat{\rho}$ such that for every firm $i \in S$ and every alternative profile of proposals $\rho_{S}^{\prime}$ made by a coalition $S \subseteq N$ it holds that

$$
\Pi_{i}(\widehat{\rho}) \geq \Pi_{i}\left(\rho_{S}^{\prime}, \widehat{\rho}_{N \backslash S}\right)
$$

Notice that while individual stability corresponds to a standard Nash equilibrium of the (strategic form) game of coalition formation, the coalitional stability condition is much more demanding. In fact, by requiring that the profile of proposals is a strong Nash equilibrium, it requires immunity against every alternative profile of proposals (including the one proposed by the grand coalition) and therefore effectively imposes Pareto-efficiency. Indeed, any Pareto-inefficient proposal would be objected by the grand coalition. Thus, whenever a particular coalition structure is coalitionally stable, it is both Pareto efficient and individually stable.

Below, we first consider individual stability before addressing the issue of coalitional stability. In both cases, our emphasis is on the aggregative rule. The reason for this is as follows. Within our setting, profits of a partial cartel $S \subset N$ are highest when its outsiders form a complementary partial cartel $\{N \backslash S\}$. This is because firms that participate in a coalition create positive externalities by setting higher prices than when they operate as independent outsiders. ${ }^{17}$ As will become clear in the following, this has the implication that if a cartel is stable under the aggregative rule it is a fortiori stable for any other coalition partition of outsiders. This includes the possibility of a fringe that exclusively consists of singletons, which effectively would be the outcome under the unanimity rule.

5.1. Individual Stability. Assuming the aggregative rule, let us begin by considering individual stability of the all-inclusive cartel. In this case, a necessary condition for the grand coalition to emerge is that each firm $i \in N$ makes the exact same proposal: $\rho_{i}=\left(\{N\}, \sigma_{N}\right)$. Whether this cartel is indeed individually stable depends on each firm's incentive to defect. Specifically, none of the producers must have an incentive to make an alternative proposal, $\rho_{i}^{\prime}=(\{i\}, 1)$, anticipating that all its rivals remain in the cartel.

Using expressions (4.7)-(4.9) and rearranging gives the deviating profits for each firm $i \in N$ :

\footnotetext{
${ }^{17}$ The oligopoly game with vertically differentiated products that we consider is, in fact, a game with positive coalition externalities, meaning that players benefit when rivals merge in coalitions. See, for instance, Marini (2009).
} 


$$
\begin{aligned}
& \Pi_{1}^{(\{1\},\{N \backslash 1\})}=\frac{v_{2}\left(v_{1}^{2}\left(c_{1}+c_{2}+\bar{\theta}\left(v_{2}-v_{1}\right)\right)-2 c_{1}\left(v_{1} v_{2}\right)\right)^{2}}{v_{1}\left(v_{2}-v_{1}\right)\left(4 v_{1} v_{2}-v_{1}^{2}\right)^{2}} \\
& \Pi_{2}^{(\{2\},\{N \backslash 2\})}=\frac{\left(v_{3}-v_{1}\right)\left(v_{2} v_{3}\left(c_{1}-2 c_{2}-\bar{\theta} v_{1}\right)+v_{2}^{2}\left(c_{2}+c_{3}-c_{1}+\bar{\theta}\left(v_{3}-v_{2}+v_{1}\right)\right)-c_{3} v_{1} v_{2}+c_{2} v_{1} v_{3}\right)^{2}}{\left(v_{3}-v_{2}\right)\left(v_{2}-v_{1}\right)\left(4 v_{2} v_{3}-v_{1} v_{3}-2 v_{1} v_{2}-v_{2}^{2}\right)^{2}}
\end{aligned}
$$

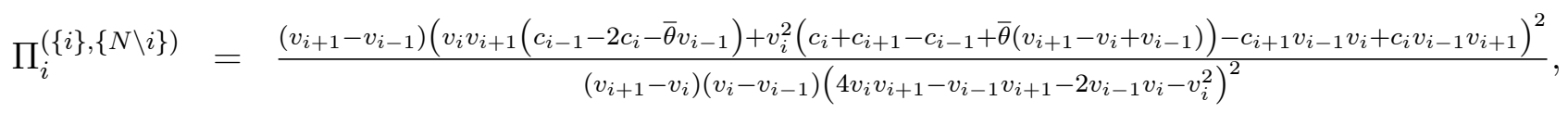

$$
\begin{aligned}
& \Pi_{n}^{(\{n\},\{N \backslash n\})=} \frac{\left(c_{n-1} v_{n}+c_{n} v_{n-1}-2 c_{n} v_{n}-2 \bar{\theta} v_{n-1} v_{n}+2 \bar{\theta} v_{n}^{2}\right)^{2}}{\left(v_{n}-v_{n-1}\right)\left(4 v_{n}-v_{n-1}\right)^{2}} .
\end{aligned}
$$

A necessary condition for the all-inclusive cartel to be individually stable under the aggregative rule is therefore that:

$$
\Pi_{N}^{(\{N\})} \geq \sum_{i=1}^{n} \Pi_{i}^{(\{i\},\{N \backslash i\})}
$$

That is, the grand coalition payoff $\Pi_{N}^{(\{N\})}$ should be sufficiently high to have each firm abide by its proposal $\rho_{i}=\left(\{N\}, \sigma_{N}\right)$.

We now explore how the cost structure affects the feasibility of the industry-wide cartel. The following proposition provides a useful benchmark by showing that the grand coalition can be made individually stable when production costs increase with quality at a fixed rate.

Proposition 5. Assume the aggregative rule and suppose that $\left|c_{j}-c_{i}\right|=c$ for any pair of adjacent firms $i, j \in N, i \neq j$ and $c_{1}=c$. There exists a sharing rule for which the all-inclusive cartel is individually stable.

The next result follows immediately.

Corollary 2 Assume the unanimity rule and suppose that $\left|c_{j}-c_{i}\right|=c$ for any pair of adjacent firms $i, j \in N, i \neq j$ and $c_{1}=c$. There exists a sharing rule for which the allinclusive cartel is individually stable.

A natural next question is how stability is affected when production costs are more or less than proportionally increasing with quality. This question is difficult to address analytically. However, numerical simulations show that stability is enhanced when costs increase less than proportionally with quality in the sense that there is a larger set of profit allocations for which the all-inclusive cartel is individually stable (see Appendix B).

When costs are increasing more than proportionally with quality, it can be easily verified that the grand coalition may no longer be individually stable provided that it only produces the top quality product. Yet, we know from Corollary 1 above that this would be suboptimal. 
Indeed, when costs are sufficiently increasing with quality, an industry-wide cartel finds it in its interest to keep all products on sale. Numerical simulations show that, although the individual stability condition tightens with the steepness of the cost curve, this also supports individual stability (see Appendix B).

As to less than all-inclusive coalitions, similar forces are at work. In fact, the key difference with the preceding analysis is the change in post-deviation profits. Whereas an individual deviation triggers a switch from monopoly to duopoly or triopoly in case of an industry-wide cartel, it causes an effectively less concentrated market structure in case of a partial cartel partition. This makes deviating ceteris paribus less attractive, which enhances individual stability.

The next two propositions confirm this for a quadropoly, again under the assumption that costs increase with quality at a constant rate.

Proposition 6. Suppose that $n=4$. Assume the aggregative rule and suppose further that $\left|c_{j}-c_{i}\right|=c$ for any pair of adjacent firms $i, j \in N, i \neq j$ and $c_{1}=c$. There exists a sharing rule for which any coalition structure is individually stable.

As before, the next result follows immediately.

Corollary 3 Suppose that $n=4$. Assume the unanimity rule and suppose that $\left|c_{j}-c_{i}\right|=c$ for any pair of adjacent firms $i, j \in N, i \neq j$ and $c_{1}=c$. There exists a sharing rule for which any coalition structure is individually stable.

These two results suggest that the logic underlying Proposition 5 and Corollary 2 applies to every partition of coalitions. Indeed, the marginal contribution of each firm to any coalition seems sufficiently high to make it feasible. In fact, given the similarity in the underlying mechanism, we conjecture this result to hold for any number of firms, although a proof of it eludes us. The overall take-away from the above analysis is then that cartels tend to be individually stable when the products involved are vertically differentiated. Whether they are also coalitionally stable is a different matter and one we now turn to.

5.2. Coalitional Stability. We now consider the possibility of deviations by groups of firms. In particular, this creates an opportunity for all firms together to decide jointly whether to form a specific coalition structure or not. As will become clear in the following, this facilitates the set-up of the most profitable agreement; an industry-wide cartel. Interestingly, Gabszewicz et al. (2016) have already shown that the core is nonempty when costs are assumed absent so that there is at least one allocation of full collusive profits that deters both individual and coalitional deviations.

To formalize, consider some coalition structure $C=\left(\left\{S_{1}\right\},\left\{S_{2}\right\}, . .,\left\{S_{k}\right\}, . .,\left\{S_{m}\right\}\right)$. Coalitional stability of the grand coalition requires that

$$
\Pi_{N}^{(\{N\})} \geq \sum_{S_{k} \in C} \Pi_{S_{k}}^{\left(\left\{S_{k}\right\},\left\{N \backslash S_{k}\right\}\right)},
$$

for any $S_{k}$ and any partition of $N \backslash S_{k}$. Provided that joint profits are allocated properly, this implies that the all-inclusive cartel is preferred to any other coalition structure.

The next two results complement the findings of Gabszewicz et al. (2016) by showing that the industry-wide cartel is the only coalitionally stable agreement when costs are increasing proportionally with quality. 
Proposition 7. Assume the aggregative rule and suppose that $\left|c_{j}-c_{i}\right|=c$ for any pair of adjacent firms $i, j \in N, i \neq j$ and $c_{1}=c$. The all-inclusive cartel is the only coalitionally stable coalition structure.

Corollary 4 Assume the unanimity rule and suppose that $\left|c_{j}-c_{i}\right|=c$ for any pair of adjacent firms $i, j \in N, i \neq j$ and $c_{1}=c$. The all-inclusive cartel is the only coalitionally stable coalition structure.

A single industry-wide cartel appears the unique coalition structure that is coalitionally stable under both the aggregative and unanimity rule when costs increase proportionally with quality. As before, numerical simulations suggest a comparable outcome when production costs increase more or less than proportionally with quality (see Appendix B). Price-fixing profits rise with cartel size(s) and this effect is sufficiently strong to prevent deviations, whether by individual producers or groups of firms.

Taken together, the findings presented in this section indicate that firms have a powerful incentive to form anticompetitive coalitions when products are vertically differentiated. By joining, producers allow the coalition to raise prices, which in turn positively affects total cartel profits. Independent of the size of the quality upgrade and corresponding production costs, this marginal contribution appears sufficiently high to make collusion an attractive alternative.

\section{Concluding Remarks}

In many markets, there is an actual or perceived difference in quality across firms and products. A recent strand of literature addresses the impact of such quality heterogeneity on firms' ability to sustain prices above competitive levels. However, all these analyses have been performed under one or two potentially restrictive assumptions. First, production costs are assumed to be independent of quality or quantity. Second, the cartel is assumed to encompass the entire industry. In this paper, we explored the extent to which these assumptions are indeed restrictive by relaxing both.

Regarding the design of optimal cartel contracts, we have shown that some of the wellestablished findings in the literature are robust to differences in unit production costs as long as these differences are sufficiently small. In particular, and independent of cartel size, the coalition has an incentive to boost sales of its top quality product and price its intermediate quality products out of the market. Yet, this changes when costs increase more than proportionally with quality. In that case, cartels prefer to set prices in such a way that all products remain on sale. As to cartel size, we find that firms have a strong incentive to collude under a range of coalition formation rules. Specifically, and for a variety of cost structures, the grand coalition can be both individually and coalitionally stable.

A natural next step is to analyze the impact of alternative cost structures and coalition formation procedures. Another promising extension is to endogenize costs or product quality (e.g., through R\&D investments). This would enable the study of so-called semi-collusion, i.e., the possibility that producers collude on price while competing in non-price dimensions (or vice versa). ${ }^{18}$ In a similar fashion, one could allow firms to offer more than one product quality variant. We leave these and related issues for future research.

\footnotetext{
${ }^{18}$ Semi-collusion is typically modelled as a two-stage game in which firms choose the non-price variable (e.g., R\&D, advertising) prior to price or output. See, for instance, Fershtman and Gandal (1994) and
} 


\section{Appendix A: Proofs}

Proof of Proposition 2. Consider an interior cartel member $i$ of a given joint-profit-maximizing partial coalition. The demand for the products of this member is given by:

$$
D_{i}^{p}=\frac{p_{i+1}^{p}-p_{i}^{p}}{v_{i+1}-v_{i}}-\frac{p_{i}^{p}-p_{i-1}^{p}}{v_{i}-v_{i-1}}=\frac{\left(v_{i}-v_{i-1}\right) \cdot p_{i+1}^{p}+\left(v_{i+1}-v_{i}\right) \cdot p_{i-1}^{p}-\left(v_{i+1}-v_{i-1}\right) \cdot p_{i}^{p}}{\left(v_{i+1}-v_{i}\right) \cdot\left(v_{i}-v_{i-1}\right)} .
$$

Its collusive best-reply is:

$$
p_{i}^{p}=\frac{\left(v_{i}-v_{i-1}\right) \cdot\left(2 p_{i+1}^{p}-c_{i+1}\right)+\left(v_{i+1}-v_{i}\right) \cdot\left(2 p_{i-1}^{p}-c_{i-1}\right)+\left(v_{i+1}-v_{i-1}\right) \cdot c_{i}}{2\left(v_{i+1}-v_{i-1}\right)} .
$$

Substituting in the demand function and rearranging gives:

$$
D_{i}^{p}=\frac{\left(v_{i}-v_{i-1}\right) \cdot c_{i+1}+\left(v_{i+1}-v_{i}\right) \cdot c_{i-1}-\left(v_{i+1}-v_{i-1}\right) \cdot c_{i}}{2\left(v_{i+1}-v_{i}\right) \cdot\left(v_{i}-v_{i-1}\right)},
$$

which is weakly negative when:

$$
\frac{c_{i+1}-c_{i}}{v_{i+1}-v_{i}} \leq \frac{c_{i}-c_{i-1}}{v_{i}-v_{i-1}}
$$

Thus, interior cartel members have no sales when costs increase weakly less than proportionally with quality.

Proof of Proposition 3. As the partial cartel is either a top quality cartel or an intermediate quality cartel, we can distinguish three types of boundary members. In case of a top quality cartel, firm $n$ is a boundary member. Its demand is:

$$
D_{n}^{p}=\frac{\left(v_{n}-v_{n-1}\right) \cdot \bar{\theta}-p_{n}^{p}+p_{n-1}^{p}}{v_{n}-v_{n-1}}
$$

Its collusive best-reply is given by:

$$
p_{n}^{p}=\frac{1}{2}\left(2 p_{n-1}^{p}-c_{n-1}+\bar{\theta}\left(v_{n}-v_{n-1}\right)\right)+\frac{1}{2} c_{n} .
$$

Substituting in the demand function and rearranging gives:

$$
D_{n}^{p}=\frac{\bar{\theta}\left(v_{n}-v_{n-1}\right)-c_{n}+c_{n-1}}{2\left(v_{n}-v_{n-1}\right)},
$$

which is strictly positive since $\bar{\theta}\left(v_{n}-v_{n-1}\right)>c_{n}-c_{n-1}$ by assumption.

Let us now turn to the other boundary member of a top quality cartel, denoted firm $i$, which faces direct competition from an outsider offering a lower-quality product. Its demand is given by:

$$
D_{i}^{p}=\frac{\left(v_{i}-v_{i-1}\right) \cdot p_{i+1}^{p}+\left(v_{i+1}-v_{i}\right) \cdot p_{i-1}-\left(v_{i+1}-v_{i-1}\right) \cdot p_{i}^{p}}{\left(v_{i+1}-v_{i}\right) \cdot\left(v_{i}-v_{i-1}\right)} .
$$

Its collusive best-reply is:

Brod and Shivakumar (1999) as well as the references therein. An extensive overview and discussion of this literature is provided by Steen and Sørgard (2009). 


$$
p_{i}^{p}=\frac{\left(v_{i}-v_{i-1}\right) \cdot\left(2 p_{i+1}^{p}-c_{i+1}\right)+\left(v_{i+1}-v_{i}\right) \cdot p_{i-1}+\left(v_{i+1}-v_{i-1}\right) \cdot c_{i}}{2\left(v_{i+1}-v_{i-1}\right)} .
$$

Substituting in its demand function and rearranging gives:

$$
D_{i}^{p}=\frac{\left(v_{i+1}-v_{i}\right) \cdot p_{i-1}+\left(v_{i}-v_{i-1}\right) \cdot c_{i+1}-\left(v_{i+1}-v_{i-1}\right) \cdot c_{i}}{2\left(v_{i+1}-v_{i}\right) \cdot\left(v_{i}-v_{i-1}\right)},
$$

which is strictly positive for $c_{i}$ sufficiently small.

Finally, let us turn to an intermediate quality cartel. Notice that its lowest-quality member finds itself in a similar position as the lowest-quality member of a top quality cartel. Following the above computations, its demand is therefore strictly positive when its unit production costs are sufficiently small. It remains to be shown that the highest-quality member of this cartel, denoted firm $j$, also has strictly positive sales. Its demand is:

$$
D_{j}^{p}=\frac{\left(v_{j}-v_{j-1}\right) \cdot p_{j+1}+\left(v_{j+1}-v_{j}\right) \cdot p_{j-1}^{p}-\left(v_{j+1}-v_{j-1}\right) \cdot p_{j}^{p}}{\left(v_{j+1}-v_{j}\right) \cdot\left(v_{j}-v_{j-1}\right)} .
$$

Its collusive best-reply is:

$$
p_{j}^{p}=\frac{\left(v_{j}-v_{j-1}\right) \cdot p_{j+1}+\left(v_{j+1}-v_{j}\right) \cdot\left(2 p_{j-1}^{p}-c_{j-1}\right)+\left(v_{j+1}-v_{j-1}\right) \cdot c_{j}}{2\left(v_{j+1}-v_{j-1}\right)} .
$$

Substituting in the demand function and rearranging gives:

$$
D_{j}^{p}=\frac{\left(v_{j}-v_{j-1}\right) \cdot p_{j+1}+\left(v_{j+1}-v_{j}\right) \cdot c_{j-1}-\left(v_{j+1}-v_{j-1}\right) \cdot c_{j}}{2\left(v_{j+1}-v_{j}\right) \cdot\left(v_{j}-v_{j-1}\right)},
$$

which is strictly positive for $c_{j}$ sufficiently small.

Proof of Proposition 4. Following the proof of Proposition 2, demand of an interior cartel member is given by:

$$
D_{i}^{p}=\frac{\left(v_{i}-v_{i-1}\right) \cdot c_{i+1}+\left(v_{i+1}-v_{i}\right) \cdot c_{i-1}-\left(v_{i+1}-v_{i-1}\right) \cdot c_{i}}{2\left(v_{i+1}-v_{i}\right) \cdot\left(v_{i}-v_{i-1}\right)},
$$

which is strictly positive when:

$$
\frac{c_{i+1}-c_{i}}{v_{i+1}-v_{i}}>\frac{c_{i}-c_{i-1}}{v_{i}-v_{i-1}}
$$

By the proof of Proposition 3, we know that firm $n$ has strictly positive sales when taking part in a top quality cartel. It remains to be shown that the same holds for the other types of boundary members.

To begin, consider a boundary member that faces direct competition from an outsider offering a lower-quality product. Following the proof of Proposition 3, its demand is given by:

$$
\begin{aligned}
D_{i}^{p} & =\frac{\left(v_{i+1}-v_{i}\right) \cdot p_{i-1}+\left(v_{i}-v_{i-1}\right) \cdot c_{i+1}-\left(v_{i+1}-v_{i-1}\right) c_{i}}{2\left(v_{i+1}-v_{i}\right) \cdot\left(v_{i}-v_{i-1}\right)} \\
& =\frac{\left(v_{i+1}-v_{i}\right) \cdot\left(p_{i-1}-c_{i-1}\right)+\left(v_{i+1}-v_{i}\right) \cdot c_{i-1}+\left(v_{i}-v_{i-1}\right) \cdot c_{i+1}-\left(v_{i+1}-v_{i-1}\right) \cdot c_{i}}{2\left(v_{i+1}-v_{i}\right) \cdot\left(v_{i}-v_{i-1}\right)},
\end{aligned}
$$


which is strictly positive when:

$$
\frac{c_{i+1}-c_{i}}{v_{i+1}-v_{i}}>\frac{c_{i}-c_{i-1}}{v_{i}-v_{i-1}}
$$

In that same proof, it was shown that the demand for the products of a boundary member facing direct competition from an outsider offering superior quality is given by:

$$
\begin{aligned}
D_{j}^{p} & =\frac{\left(v_{j}-v_{j-1}\right) \cdot p_{j+1}+\left(v_{j+1}-v_{j}\right) \cdot c_{j-1}-\left(v_{j+1}-v_{j-1}\right) \cdot c_{j}}{2\left(v_{j+1}-v_{j}\right) \cdot\left(v_{j}-v_{j-1}\right)} \\
& =\frac{\left(v_{j}-v_{j-1}\right) \cdot\left(p_{j+1}-c_{j+1}\right)+\left(v_{j}-v_{j-1}\right) \cdot c_{j+1}+\left(v_{j+1}-v_{j}\right) \cdot c_{j-1}-\left(v_{j+1}-v_{j-1}\right) \cdot c_{j}}{2\left(v_{j+1}-v_{j}\right) \cdot\left(v_{j}-v_{j-1}\right)},
\end{aligned}
$$

which is strictly positive when:

$$
\frac{c_{j+1}-c_{j}}{v_{j+1}-v_{j}}>\frac{c_{j}-c_{j-1}}{v_{j}-v_{j-1}} .
$$

Finally, in case of a bottom quality cartel, there is a boundary member not facing direct competition from an outsider (firm 1). Its demand is given by:

$$
D_{1}^{p}=\frac{p_{2}^{p}-p_{1}^{p}}{v_{2}-v_{1}}-\frac{p_{1}^{p}}{v_{1}}
$$

Its collusive best-reply is:

$$
p_{1}^{p}=\frac{v_{1}}{2 v_{2}} \cdot\left(2 p_{2}^{p}-c_{2}\right)+\frac{1}{2} c_{1} .
$$

Substituting in its demand function and rearranging gives:

$$
D_{1}^{p}=\frac{v_{1} c_{2}-v_{2} c_{1}}{2 v_{1}\left(v_{2}-v_{1}\right)}
$$

which is strictly positive when:

$$
\frac{c_{2}}{c_{1}}>\frac{v_{2}}{v_{1}}
$$

We thus conclude that for some given partial cartel, all members have strictly positive sales when costs increase more than proportionally with quality.

Proof of Proposition 5. By assumption, $\left|c_{j}-c_{i}\right|=c$ for any pair of adjacent firms $i, j \in$ $N, i \neq j$ and $c_{1}=c$. Following Corollary 1, the profit-maximizing cartel contract in this case stipulates $D_{n}^{c}>0$ and $D_{i}^{c}=0$, for all $i \neq n$. Therefore, total collusive profits are given by

$$
\Pi_{N}^{(\{N\})}=\Pi_{n}^{c}=\frac{n \cdot(\bar{\theta} d-c)^{2}}{4 d} .
$$

Using (5.1) and propositions 2 and 3, the individual stability condition (5.2) can then be written as

$$
\frac{n \cdot(\bar{\theta} d-c)^{2}}{4 d} \geq \sum_{i=1}^{n-1} \frac{2(i)^{2} \cdot(\bar{\theta} d-c)^{2}}{(6(i)+1)^{2} d}+\frac{4 n^{2} \cdot(\bar{\theta} d-c)^{2}}{(3 n+1)^{2} d} .
$$

Rearranging gives 


$$
1 \geq \sum_{i=1}^{n-1} \frac{8(i)^{2}}{(6(i)+1)^{2} n}+\frac{16 n}{(3 n+1)^{2}}
$$

which holds for $n \geq 2$. Thus, there exists a sharing rule, $\sigma_{N}=\left\{\sigma_{i}\right\}_{i \in N}$, for which the all-inclusive cartel is individually stable.

Proof of Proposition 6. Note that a coalition structure exclusively consisting of singletons is trivially individually stable and that there exists a sharing rule for which the grand coalition is individually stable (Proposition 5). Furthermore, it can be easily verified that any partial cartel comprising two firms is individually stable when it faces competition from a fringe of independent outsiders since deviating would result in the 'competitive' Nash outcome.

Given that $n=4$, this leaves three coalition structures that we now discuss in turn.

To begin, consider the bottom cartel comprising three firms. Joint profits are given by:

$$
\Pi_{123}^{(\{123\},\{4\})}=\left(p_{1}^{p}-c\right)\left[\frac{p_{2}^{p}-2 p_{1}^{p}}{d}\right]+\left(p_{2}^{p}-2 c\right)\left[\frac{p_{3}^{p}+p_{1}^{p}-2 p_{2}^{p}}{d}\right]+\left(p_{3}^{p}-3 c\right)\left[\frac{p_{4}+p_{2}^{p}-2 p_{3}^{p}}{d}\right] .
$$

Using the first-order conditions, this yields the following best-responses:

$$
\begin{aligned}
p_{1}^{p} & =\frac{1}{2} p_{2}^{p} \\
p_{2}^{p} & =\frac{1}{2} p_{1}^{p}+\frac{1}{2} p_{3}^{p}, \\
p_{3}^{p} & =\frac{1}{2} p_{2}^{p}+\frac{1}{4} p_{4}+c, \\
p_{4} & =\frac{1}{2} p_{3}^{p}+\frac{1}{2} \bar{\theta} d+2 c .
\end{aligned}
$$

Combining gives the optimal prices:

$$
\begin{aligned}
& p_{1}^{p}=\frac{\bar{\theta} d+12 c}{13}, \\
& p_{2}^{p}=\frac{2 \bar{\theta} d+24 c}{13}, \\
& p_{3}^{p}=\frac{3 \bar{\theta} d+36 c}{13}, \\
& p_{4}=\frac{8 \bar{\theta} d+44 c}{13} .
\end{aligned}
$$

Substituting in the cartel's objective function gives:

$$
\Pi_{123}^{(\{123\},\{4\})}=\frac{12(\bar{\theta} d-c)^{2}}{169 d} .
$$

The optimal deviating profit of each member $\left(\Pi_{i}^{d}\right)$ of this cartel under the aggregative rule is, respectively, given by: 


$$
\begin{aligned}
& \Pi_{1}^{d} \equiv \Pi_{1}^{(\{1\},\{23\},\{4\})}=\frac{8(\bar{\theta} d-c)^{2}}{5329 d}, \\
& \Pi_{2}^{d} \equiv \Pi_{2}^{(\{1\},\{2\},\{3\},\{4\})}=\frac{32(\bar{\theta} d-c)^{2}}{9409 d}, \\
& \Pi_{3}^{d} \equiv \Pi_{3}^{(\{12\},\{3\},\{4\})}=\frac{72(\bar{\theta} d-c)^{2}}{1444 d} .
\end{aligned}
$$

Individual stability therefore requires:

$$
\frac{12(\bar{\theta} d-c)^{2}}{169 d} \geq \frac{8(\bar{\theta} d-c)^{2}}{5329 d}+\frac{32(\bar{\theta} d-c)^{2}}{9409 d}+\frac{72(\bar{\theta} d-c)^{2}}{1444 d}
$$

which holds. Hence, there exists a sharing rule for which the bottom quality cartel comprising three firms is individually stable.

Next, let us consider the top quality cartel comprising three firms. In this case, joint profits are:

$\Pi_{234}^{(\{1\},\{234\})}=\left(p_{2}^{p}-2 c\right)\left[\frac{p_{1}+p_{3}^{p}-2 p_{2}^{p}}{d}\right]+\left(p_{3}^{p}-3 c\right)\left[\frac{p_{2}^{p}+p_{4}^{p}-2 p_{3}^{p}}{d}\right]+\left(p_{4}^{p}-4 c\right)\left[\frac{\bar{\theta} d-p_{4}^{p}+p_{3}^{p}}{d}\right]$.

Using the first-order conditions and combining gives the optimal prices:

$$
\begin{aligned}
p_{1} & =\frac{2 \bar{\theta} d+12 c}{14}, \\
p_{2}^{p} & =\frac{8 \bar{\theta} d+20 c}{14}, \\
p_{3}^{p} & =\frac{15 \bar{\theta} d+27 c}{14}, \\
p_{4}^{p} & =\frac{22 \bar{\theta} d+34 c}{14} .
\end{aligned}
$$

Substituting in the cartel's objective function gives:

$$
\Pi_{234}^{(\{1\},\{234\})}=\frac{162(\bar{\theta} d-c)^{2}}{196 d} .
$$

The optimal deviating profit of each member $\left(\Pi_{i}^{d}\right)$ from this cartel is, respectively, given by:

$$
\begin{aligned}
& \Pi_{2}^{d} \equiv \Pi_{2}^{(\{1\},\{2\},\{34\})}=\frac{32(\bar{\theta} d-c)^{2}}{676 d}, \\
& \Pi_{3}^{d} \equiv \Pi_{3}^{(\{1\},\{2\},\{3\},\{4\})}=\frac{450(\bar{\theta} d-c)^{2}}{9409 d}, \\
& \Pi_{4}^{d} \equiv \Pi_{4}^{(\{1\},\{23\},\{4\})}=\frac{1936(\bar{\theta} d-c)^{2}}{5329 d} .
\end{aligned}
$$

Individual stability therefore requires:

$$
\frac{162(\bar{\theta} d-c)^{2}}{196 d} \geq \frac{32(\bar{\theta} d-c)^{2}}{676 d}+\frac{450(\bar{\theta} d-c)^{2}}{9409 d}+\frac{1936(\bar{\theta} d-c)^{2}}{5329 d},
$$


which holds. Hence, there exists a sharing rule for which the top quality cartel comprising three firms is individually stable.

Finally, let us consider the possibility that firms 1 and 2 and firms 3 and 4 collude. In this case, joint profits are, respectively, given by:

$$
\begin{aligned}
\Pi_{12}^{(\{12\},\{34\})} & =\left(p_{1}^{p}-c\right)\left[\frac{p_{2}^{p}-2 p_{1}^{p}}{d}\right]+\left(p_{2}^{p}-2 c\right)\left[\frac{p_{3}^{p}+p_{1}^{p}-2 p_{2}^{p}}{d}\right], \\
\Pi_{34}^{(\{12\},\{34\})} & =\left(p_{3}^{p}-3 c\right)\left[\frac{p_{2}^{p}+p_{4}^{p}-2 p_{3}^{p}}{d}\right]+\left(p_{4}^{p}-4 c\right)\left[\frac{\bar{\theta} d-p_{4}^{p}+p_{3}^{p}}{d}\right] .
\end{aligned}
$$

As before, using the first-order conditions and combining gives the optimal prices:

$$
\begin{aligned}
p_{1}^{p} & =\frac{\bar{\theta} d+9 c}{10}, \\
p_{2}^{p} & =\frac{2 \bar{\theta} d+18 c}{10}, \\
p_{3}^{p} & =\frac{6 \bar{\theta} d+24 c}{10}, \\
p_{4}^{p} & =\frac{11 \bar{\theta} d+29 c}{10} .
\end{aligned}
$$

Substituting in the objective functions gives:

$$
\begin{aligned}
& \Pi_{12}^{(\{12\},\{34\})}=\frac{6(\bar{\theta} d-c)^{2}}{100 d}, \\
& \Pi_{34}^{(\{12\},\{34\})}=\frac{61(\bar{\theta} d-c)^{2}}{100 d} .
\end{aligned}
$$

The optimal deviating profit of each member $\left(\Pi_{i}^{d}\right)$ is, respectively, given by:

$$
\begin{aligned}
& \Pi_{1}^{d} \equiv \Pi_{1}^{(\{1\},\{2\},\{34\})}=\frac{2(\bar{\theta} d-c)^{2}}{676 d}, \\
& \Pi_{2}^{d} \equiv \Pi_{2}^{(\{1\},\{2\},\{34\})}=\frac{32(\bar{\theta} d-c)^{2}}{676 d}, \\
& \Pi_{3}^{d} \equiv \Pi_{3}^{(\{12\},\{3\},\{4\})}=\frac{72(\bar{\theta} d-c)^{2}}{1444 d} \\
& \Pi_{4}^{d} \equiv \Pi_{4}^{(\{12\},\{3\},\{4\})}=\frac{484(\bar{\theta} d-c)^{2}}{1444 d} .
\end{aligned}
$$

Individual stability of both coalitions therefore requires:

$$
\begin{aligned}
\frac{6(\bar{\theta} d-c)^{2}}{100 d} & \geq \frac{2(\bar{\theta} d-c)^{2}}{676 d}+\frac{32(\bar{\theta} d-c)^{2}}{676 d}, \text { and } \\
\frac{61(\bar{\theta} d-c)^{2}}{100 d} & \geq \frac{72(\bar{\theta} d-c)^{2}}{1444 d}+\frac{484(\bar{\theta} d-c)^{2}}{1444 d},
\end{aligned}
$$

which holds. We conclude that for each coalition structure there exists a sharing rule for which it is individually stable. 
Proof of Proposition 7. Let us start by showing that there exists an allocation rule for which the all-inclusive cartel is coalitionally stable. Towards that end, consider a sharing rule, $\sigma_{N}=\left(\sigma_{1}, \sigma_{2}, \ldots, \sigma_{n}\right)$, which assigns the following share of the full collusive payoff $\Pi_{N}^{(\{N\})}$ to every firm $i \in N$ :

$$
\widetilde{\sigma}_{i}=\frac{\Pi_{i}^{(\{i\},\{N \backslash i\})}}{\sum_{i \in N} \Pi_{i}^{(\{i\},\{N \backslash i\})}}
$$

Thus, each firm is allocated a share proportional to its deviating profits, which results in the following profit allocation:

$$
a_{N}=\left(\widetilde{\sigma}_{1} \Pi_{N}^{(\{N\})}, \widetilde{\sigma}_{i} \Pi_{N}^{(\{N\})}, \ldots, \widetilde{\sigma}_{n} \Pi_{N}^{(\{N\})}\right)
$$

As a first observation, note that, by construction, it holds that

$$
\widetilde{\sigma}_{i} \Pi_{N}^{(\{N\})} \geq \widetilde{\sigma}_{i} \sum_{i \in N} \Pi_{i}^{(\{i\},\{N \backslash i\})}=\Pi_{i}^{(\{i\},\{N \backslash i\})}, \forall i \in N,
$$

so that the proposal $\rho_{i}=\left(\{N\}, \sigma_{N}\right)$ is robust to individual deviations.

Next, let us consider the possibility of coalitional deviations. To begin, consider a deviating bottom quality cartel $S_{B} \subset N$. Under the aggregative rule, such a deviation would lead to the coalition structure $C=\left(\left\{S_{B}\right\},\left\{N \backslash S_{B}\right\}\right)$. Since $\left|c_{j}-c_{i}\right|=c$ for any pair of adjacent firms $i, j \in N, i \neq j$ and $c_{1}=c$ by assumption, we know by the proof of Proposition 3 that only the boundary variants $v_{b}, v_{b+1}$ and $v_{n}$ remain on sale $\left(v_{b}\right.$ from $S_{B}$ and $v_{b+1}$ and $v_{n}$ from $\left.N \backslash S_{B}\right)$. Specifically, $v_{b}$ is the highest quality variant offered by the bottom quality cartel. Its profits are then given by:

$$
\Pi_{S_{B}}^{\left(\left\{S_{B}\right\},\left\{N \backslash S_{B}\right\}\right)}=\prod_{b=\max \{i\}_{i \in S_{B}}}^{\left(\left\{S_{B}\right\},\left\{N \backslash S_{B}\right\}\right)}=\frac{(\bar{\theta} d-c)^{2} b(b+1)}{(3 b+4)^{2} d} .
$$

Notice that $b$ also denotes the cardinality of the bottom cartel $S_{B}$, i.e., $\left|S_{B}\right|=b$. Hence, following the sharing rule (7.2) and the associated profit allocation (7.3), the inequality

$$
\sum_{i \in S_{B}} \widetilde{\sigma}_{i} \Pi^{(\{N\})} \geq \Pi_{S_{B}}^{\left(\left(\left\{S_{B}\right\},\left\{N \backslash S_{B}\right\}\right)\right)}
$$

can be written as

$$
\frac{\sum_{i=1}^{b} \frac{2(i)^{2}(\bar{\theta} d-c)^{2}}{(6(i)+1)^{2} d}}{\sum_{i=1}^{n-1} \frac{2(i)^{2} \cdot(\bar{\theta} d-c)^{2}}{(6(i)+1)^{2} d}+\frac{4(\bar{\theta} d-c)^{2} n^{2}}{(3 n+1)^{2} d}} \frac{n(\bar{\theta} d-c)^{2}}{4 d} \geq \frac{(\bar{\theta} d-c)^{2} b(b+1)}{(3 b+4)^{2} d}
$$

or

$$
\frac{\sum_{i=1}^{b} \frac{2(i)^{2}}{(6(i)+1)^{2}}}{\sum_{i=1}^{n-1} \frac{2(i)^{2}}{(6(i)+1)^{2}}+\frac{4 n^{2}}{(3 n+1)^{2}}} \frac{n}{4} \geq \frac{b(b+1)}{(3 b+4)^{2}}
$$


which holds for any $n \geq 2$ and $b=2, \ldots n-1$. Therefore, if (7.6) is satisfied, then a bottom quality cartel $S_{B}$ cannot profitably defects from the all-inclusive cartel when sharing rule (7.2) is used to distribute the grand coalition payoff.

Let us now turn to a potentially deviating top quality cartel $S_{T} \subset N$, which under the aggregative rule would lead to a coalition structure $C=\left(\left\{S_{T}\right\},\left\{N \backslash S_{T}\right\}\right)$. By the proof of Proposition 3, only three variants remain on sale in this case; variant $v_{b-1}$ from $N \backslash S_{T}$ and variants $v_{b}$ and $v_{n}$ from $S_{T}$. Here, $b$ denotes the lowest quality firm in $S_{T}$. Profits of cartel $S_{T}$ are then given by:

$$
\begin{aligned}
\Pi_{S_{T}}^{\left(\left\{S_{T}\right\},\left\{N \backslash S_{T}\right\}\right)=} & \Pi_{b=\min \{i\}_{i \in S_{T}}}+\Pi_{n}= \\
& \frac{(\bar{\theta} d-c)^{2}(b-1) b}{(3 b+1)^{2} d}+\frac{1}{4} \frac{(\bar{\theta} d-c)^{2}\left(3 b+n+3 b n-3 b^{2}\right)}{(3 b+1) d} .
\end{aligned}
$$

In this case, the inequality

$$
\sum_{i \in S_{T}} \widetilde{\sigma}_{i} \Pi^{(\{N\})} \geq \Pi_{S_{T}}^{\left(\left\{S_{T}\right\},\left\{N \backslash S_{T}\right\}\right)}
$$

can be written as

$$
\begin{aligned}
& \sum_{i=b}^{n-1} \frac{2(i)^{2}(\bar{\theta} d-c)^{2}}{(6(i)+1)^{2} d}+\frac{4(\bar{\theta} d-c)^{2} n^{2}}{(3 n+1)^{2} d} \\
& \sum_{i=1}^{n-1} \frac{2(i)^{2}(\bar{\theta} d-c)^{2}}{(6(i)+1)^{2} d}+\frac{4(\bar{\theta} d-c)^{2} n^{2}}{(3 n+1)^{2} d} \frac{n(\bar{\theta} d-c)^{2}}{4 d} \geq \frac{(\bar{\theta} d-c)^{2} b(b-1)}{(3 b+1)^{2} d}+ \\
& \frac{1}{4} \frac{\left(3 b+n+3 b n-3 b^{2}\right)(\bar{\theta} d-c)^{2}}{(3 b+1) d}
\end{aligned}
$$

which reduces to

$$
\frac{\sum_{i=b}^{n-1} \frac{2(i)^{2}}{(6(i)+1)^{2}}+\frac{4 n^{2}}{(3 n+1)^{2}}}{\sum_{i=1}^{n-1} \frac{2(i)^{2}}{(6(i)+1)^{2}}+\frac{4 n^{2}}{(3 n+1)^{2}}} \frac{n}{4} \geq \frac{b(b-1)}{(3 b+1)^{2}}+\frac{1}{4} \frac{\left(3 b+n+3 b n-3 b^{2}\right)}{(3 b+1)},
$$

which holds for any $n \geq 2$ and $b=2, \ldots n-1$. Thus, a top quality cartel $S_{T}$ never profitably defects from the grand coalition when sharing rule (7.2) is used to distribute the all-inclusive cartel profit.

Finally, should an intermediate quality cartel $S_{I} \subset N$ leave the grand coalition, the following coalition structure would arise under the aggregative rule: $C=\left(\left\{S_{B}\right\},\left\{S_{I}\right\},\left\{S_{T}\right\}\right)$. In this case, and following the proof of Proposition 3, at most five variants would remain on sale: $v_{b-1}$ from $S_{B}, v_{b}$ and $v_{t}$ from $S_{I}$, and $v_{t+1}$ and $v_{n}$ from $S_{T}$, where $b$ and $t$ denote the bottom and top quality firm in the intermediate cartel $S_{I}$, respectively. The payoff obtained by an intermediate cartel is then given by: 


$$
\begin{aligned}
\Pi_{S_{I}}^{\left(\left\{S_{B}\right\},\left\{S_{I}\right\},\left\{S_{T}\right\}\right)=} & \Pi_{b=\min \{i\}_{i \in S_{I}}}+\Pi_{t=\max \{i\}_{i \in S_{I}}}= \\
& \frac{4 b(b-1)(d \bar{\theta}-c)^{2} d}{\left(9 b^{2}-4-21 b-3 t-9 b t\right)^{2}}+ \\
& \frac{\left(3 b^{2}-1-6 b-t-3 b t\right)\left(3 b^{2}-3 b-t-3 b t\right)(d \bar{\theta}-c)^{2} d}{\left(9 b^{2}-4-21 b-3 t-9 b t\right)^{2}} .
\end{aligned}
$$

As a result, the inequality

$$
\sum_{i \in S_{I}} \widetilde{\sigma}_{i} \Pi_{N}^{(\{N\})} \geq \Pi_{S_{I}}^{\left(\left\{S_{I}\right\},\left\{N \backslash S_{I}\right\}\right)}
$$

can be written as

$$
\begin{aligned}
& \frac{\sum_{i=b}^{t} \frac{2(i)^{2}(\bar{\theta} d-c)^{2}}{(6(i)+1)^{2} d}}{\sum_{i=1}^{n-1} \frac{2(i)^{2}(\bar{\theta} d-c)^{2}}{(6(i)+1)^{2} d}+\frac{4(\bar{\theta} d-c)^{2} n^{2}}{(3 n+1)^{2} d}} \frac{n(\bar{\theta} d-c)^{2}}{4 d} \geq \frac{4 b(b-1)(\bar{\theta} d-c)^{2} d}{\left(9 b^{2}-4-21 b-3 t-9 b t\right)^{2}}+ \\
& \frac{\left(3 b^{2}-1-6 b-t-3 b t\right)\left(3 b^{2}-3 b-t-3 b t\right)(\bar{\theta} d-c)^{2} d}{\left(9 b^{2}-4-21 b-3 t-9 b t\right)^{2}}
\end{aligned}
$$

which reduces to

$$
\frac{\sum_{i=b}^{t} \frac{2(i)^{2}}{(6(i)+1)^{2}}}{\sum_{i=1}^{n-1} \frac{2(i)^{2}}{(6(i)+1)^{2}}+\frac{4 n^{2}}{(3 n+1)^{2}}} \frac{n}{4} \geq \frac{4 b(b-1)}{\left(9 b^{2}-4-21 b-3 t-9 b t\right)^{2}}+\frac{\left(3 b^{2}-1-6 b-t-3 b t\right)\left(3 b^{2}-3 b-t-3 b t\right)}{\left(9 b^{2}-4-21 b-3 t-9 b t\right)^{2}},
$$

which holds for any $n \geq 2, b=2, \ldots n-2$ and $t=3, \ldots, n-1$, with $t>b$. We conclude that there exists a sharing rule for which the all-inclusive cartel is coalitionally stable.

To see that this is the only coalitionally stable coalition structure, notice that by the property of the sharing rule, $\sum_{S_{k} \in C} \widetilde{\sigma}_{S_{k}}=1$, the inequality

$$
\Pi_{N}^{(\{N\})} \geq \sum_{S_{k} \in C^{\prime}} \Pi_{S_{k}}^{C^{\prime}}
$$

necessarily holds, where $C^{\prime} \in \mathcal{C}^{A}(N)$ indicates the subset of all feasible coalition structures that arise under the aggregative rule resulting from a cartel (or individual firm) leaving the grand coalition. Since every cartel benefits when rivals form coarser coalitions (due to the presence of positive coalition externalities), however, condition (7.9) implies that the industry-wide cartel generates more profits than the combined profits of all firms organized in any other possible coalition structure $C \in \mathcal{C}(N)$, i.e.,

$$
\Pi_{N}^{(\{N\})} \geq \sum_{S_{k} \in C} \Pi_{S_{k}}^{C}
$$

As the expressions (5.2), (7.5), (7.7) and (7.8) are all satisfied with strict inequality, this extends to conditions (7.9) and (7.10). Every coalition structure different from the grand 
coalition can therefore be objected by all firms together as they can form the more profitable all-inclusive cartel instead.

\section{Appendix B: Simulations}

Propositions 5-7 have been derived under the assumption that costs increase proportionally with quality. In this appendix, we will examine individual and coalitional stability under the aggregative rule when costs are increasing more or less than proportionally. Towards that end, we present some numerical simulations assuming full collusion and $n=4$. We further assume:

$$
\begin{aligned}
& v_{1}=d, v_{2}=2 d, v_{3}=3 d, v_{4}=4 d \\
& c_{1}=d^{\frac{1}{a}}, c_{2}=(2 d)^{\frac{1}{a}}, c_{3}=(3 d)^{\frac{1}{a}}, c_{4}=(4 d)^{\frac{1}{a}} .
\end{aligned}
$$

Notice that costs increase less (more) than proportionally with quality when $a>1(0<a<$ 1).

8.1. Individual Stability. Using (5.1), the aggregative rule yields the following individual firms' deviating payoffs when costs increase less than proportionally with quality (i.e., $a>$ 1):

$$
\begin{aligned}
& \Pi_{1}^{(\{1\},\{234\})}=\frac{2\left(\bar{\theta} d-3 d^{\frac{1}{a}}+(2 d)^{\frac{1}{a}}\right)^{2}}{49 d},
\end{aligned}
$$

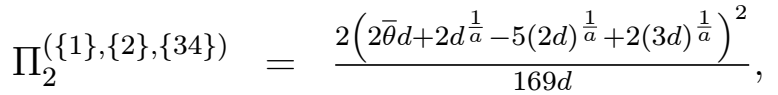

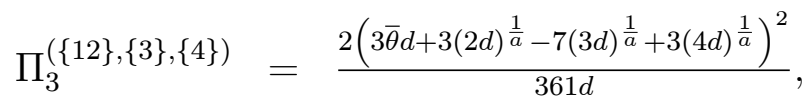

$$
\begin{aligned}
& \Pi_{4}^{(\{123\},\{4\})}=\frac{\left(8 \bar{\theta} d+4(3 d)^{\frac{1}{a}}-5(4 d)^{\frac{1}{a}}\right)^{2}}{169 d} .
\end{aligned}
$$

By Corollary 1, the all-inclusive cartel only sells its top quality variant when $a \geq 1$ with corresponding profits:

$$
\Pi_{N}^{(\{1234\})}=\frac{1}{4}\left(\bar{\theta} v_{4}-c_{4}\right)\left(\bar{\theta}-\frac{c_{4}-c_{3}}{v_{4}-v_{3}}\right)=\frac{\left(\bar{\theta} d+(3 d)^{\frac{1}{a}}-(4 d)^{\frac{1}{a}}\right)\left(4 \bar{\theta} d-(4 d)^{\frac{1}{a}}\right)}{4 d} .
$$

In this case, the individual stability condition (5.2) can be written as:

$$
\begin{aligned}
\frac{\left(\bar{\theta} d+(3 d)^{\frac{1}{a}}-(4 d)^{\frac{1}{a}}\right)\left(4 \bar{\theta} d-(4 d)^{\frac{1}{a}}\right)}{4 d} \geq & \frac{2\left(\bar{\theta} d-3 d^{\frac{1}{a}}+2^{\frac{1}{a}} d^{\frac{1}{a}}\right)^{2}}{49 d}+\frac{2\left(2 \bar{\theta} d+2 d^{\frac{1}{a}}-5(2 d)^{\frac{1}{a}}+2(3 d)^{\frac{1}{a}}\right)^{2}}{169 d}+ \\
& \frac{2\left(3 \bar{\theta} d+3 \cdot 2^{\frac{2}{a}} d^{\frac{1}{a}}+3 \cdot 2^{\frac{1}{a}} d^{\frac{1}{a}}-7 \cdot 3^{\frac{1}{a}} d^{\frac{1}{a}}\right)^{2}}{361 d}+\frac{\left(8 \bar{\theta} d+4(3 d)^{\frac{1}{a}}-5(4 d)^{\frac{1}{a}}\right)^{2}}{169 d} .
\end{aligned}
$$

Figure 1 below compares the grand coalition payoff (solid red line) with the sum of deviating firms' payoffs (dashed black line). Note that when $a$ increases, the difference in profits increases. This difference is depicted in Figure 2. 


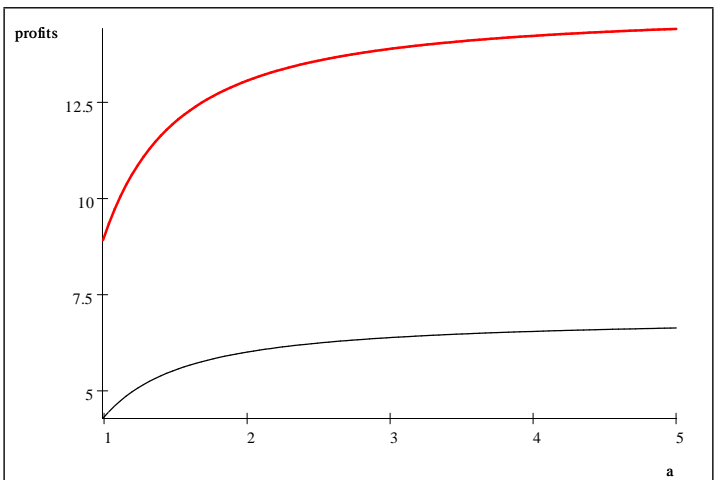

Figure 1 - All-inclusive cartel profit (red line) and sum of all deviating firms' profits (black line) for $a \in[1,5]$.

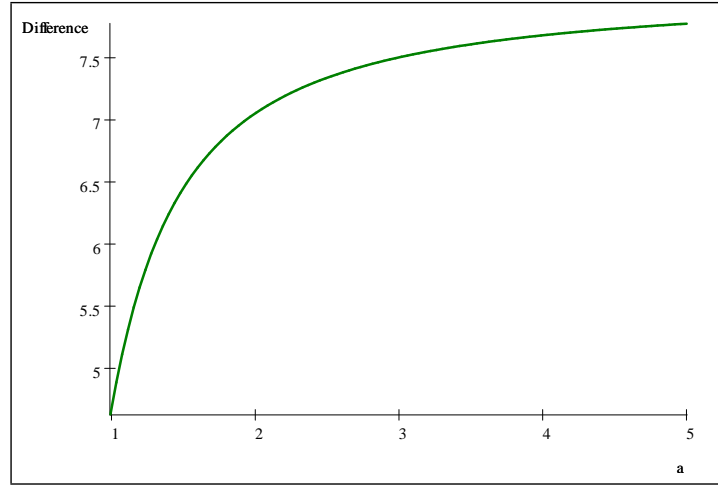

Figure 2 - Difference between the all-inclusive cartel profit and the sum of all deviating firms' profits for $a \in[1,5]$.

Instead, if costs increase more than proportionally with quality (i.e., $0<a<1$ ), then all variants remain on sale (Corollary 1). In this case, full collusive profits are given by:

$$
\begin{aligned}
\Pi_{N}^{(\{1234\})=} & \frac{1}{4}\left(\bar{\theta} v_{1}-c_{1}\right)\left(\frac{c_{2}-c_{1}}{v_{2}-v_{1}}-\frac{c_{1}}{v_{1}}\right)+\frac{1}{4}\left(\bar{\theta} v_{2}-c_{2}\right)\left(\frac{c_{3}-c_{2}}{v_{3}-v_{2}}-\frac{c_{2}-c_{1}}{v_{2}-v_{1}}\right)+ \\
& \frac{1}{4}\left(\bar{\theta} v_{3}-c_{3}\right)\left(\frac{c_{4}-c_{3}}{v_{4}-v_{3}}-\frac{c_{3}-c_{2}}{v_{3}-v_{2}}\right)+\frac{1}{4}\left(\bar{\theta} v_{4}-c_{4}\right)\left(\bar{\theta}-\frac{c_{4}-c_{3}}{v_{4}-v_{3}}\right) \\
= & \frac{4 d^{2} \bar{\theta}^{2}+2 d^{\frac{2}{a}}-2 d \bar{\theta}(4 d)^{\frac{1}{a}}+2(2 d)^{\frac{2}{a}}+2(3 d)^{\frac{2}{a}}+(4 d)^{\frac{2}{a}}-2 d^{\frac{1}{a}}(2 d)^{\frac{1}{a}}-2(2 d)^{\frac{1}{a}}(3 d)^{\frac{1}{a}}-2(3 d)^{\frac{1}{a}}(4 d)^{\frac{1}{a}}}{4 d} .
\end{aligned}
$$

The individual stability condition (5.2) can then be written as:

$$
\begin{aligned}
& \frac{1}{4} \frac{4 d^{2} \bar{\theta}^{2}+2 d^{\frac{2}{a}}-2 d \bar{\theta}(4 d)^{\frac{1}{a}}+2(2 d)^{\frac{2}{a}}+2(3 d)^{\frac{2}{a}}+(4 d)^{\frac{2}{a}}-2 d^{\frac{1}{a}}(2 d)^{\frac{1}{a}}-2(2 d)^{\frac{1}{a}}(3 d)^{\frac{1}{a}}-2(3 d)^{\frac{1}{a}}(4 d)^{\frac{1}{a}}}{d} \\
\geq & \frac{2\left(d \bar{\theta}-3 d^{\frac{1}{a}}+(2 d)^{\frac{1}{a}}\right)^{2}}{49 d}+\frac{2\left(2 \bar{\theta} d+2 d^{\frac{1}{a}}-5(2 d)^{\frac{1}{a}}+2(3 d)^{\frac{1}{a}}\right)^{2}}{169 d} \\
& +\frac{2\left(3 \bar{\theta} d+3(2 d)^{\frac{1}{a}}-7(3 d)^{\frac{1}{a}}+3(4 d)^{\frac{1}{a}}\right)^{2}}{361 d}+\frac{\left(8 \bar{\theta} d+4(3 d)^{\frac{1}{a}}-5(4 d)^{\frac{1}{a}}\right)^{2}}{169 d} .
\end{aligned}
$$

Figure 3 plots the grand coalition payoff (solid red line) and the sum of deviating firms' payoffs (dashed black line) as a function of $a$, for $a \in[0.3,0.6]{ }^{19}$ Notice that the difference decreases in $a$, but remains positive everywhere (Figure 4).

\footnotetext{
${ }^{19}$ Similar qualitative results hold for any $a \in(0,1)$ although, for convenience, in figures we plot the expressions only for $a \in[0.3,0.6]$.
} 


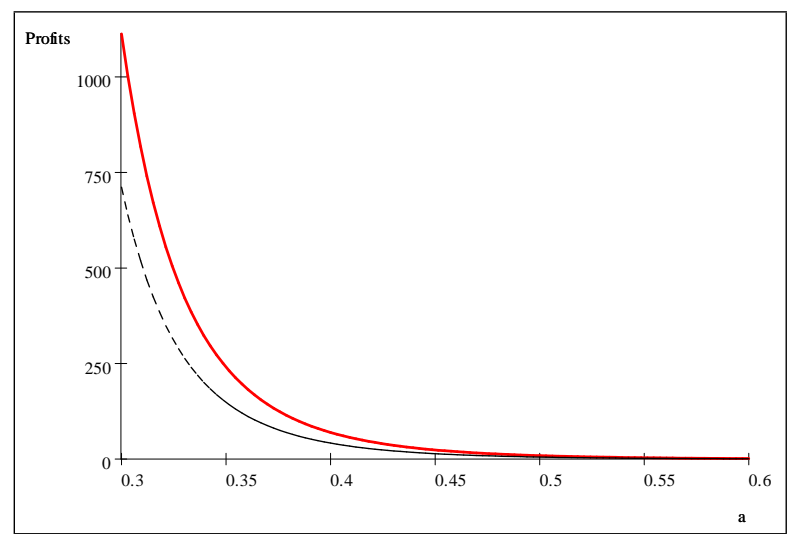

Figure 3 - All-inclusive cartel profit (red line) and sum of all deviating firms' profits

(black dashed line) for $a \in[0.3,0.6]$.

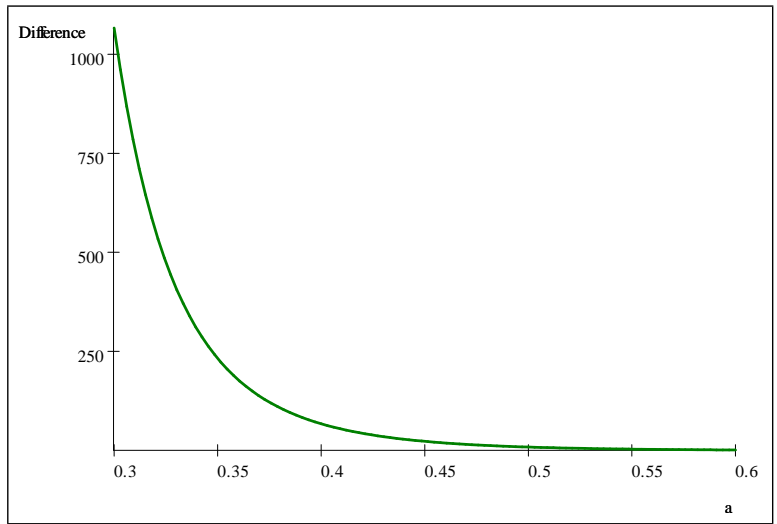

Figure 4 - Difference between the all-inclusive cartel and the sum of all deviating firms' profits for $a \in[0.3,0.6]$.

Taken together, the above simulations suggest that Proposition 5 and Proposition 6 also hold when costs are more or less than proportionally increasing with quality.

8.2. Coalitional Stability. Let us now analyze coalitional stability when costs increase less than proportionally with quality. To begin, consider the coalition structure $C=$ $(\{1\},\{2\},\{3\},\{4\})$ in which all firms compete as individual firms. In this case, their profits are respectively given by:

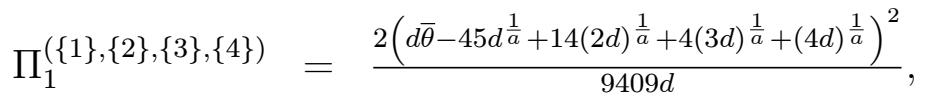

$$
\begin{aligned}
& \Pi_{2}^{(\{1\},\{2\},\{3\},\{4\})}=\frac{2\left(4 d \bar{\theta}+14 d^{\frac{1}{a}}-41(2 d)^{\frac{1}{a}}+16(3 d)^{\frac{1}{a}}+4(4 d)^{\frac{1}{a}}\right)^{2}}{9409 d} \\
& \Pi_{3}^{(\{1\},\{2\},\{3\},\{4\})}=\frac{2\left(15 d \bar{\theta}+4 d^{\frac{1}{a}}+16(2 d)^{\frac{1}{a}}-37(3 d)^{\frac{1}{a}}+15(4 d)^{\frac{1}{a}}\right)^{2}}{9409 d},
\end{aligned}
$$

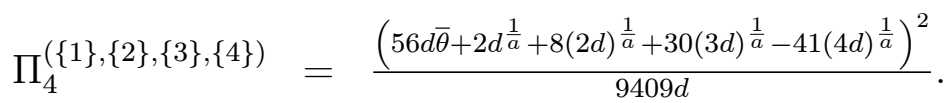

Next, let us specify the payoffs for all coalition structures with one or more partial cartels. The following profits are obtained, respectively, for coalition structure $C=(\{12\},\{3\},\{4\})$,

for $C=(\{12\},\{34\})$,

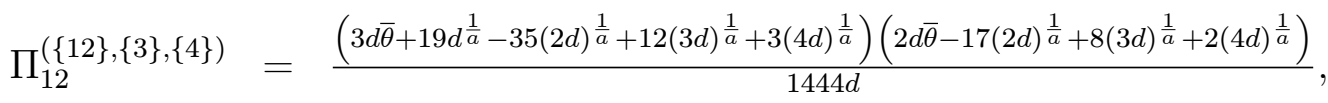

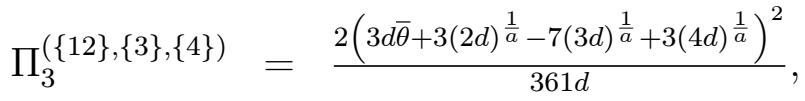

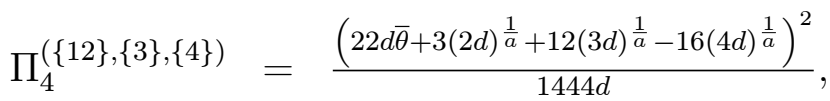




$$
\begin{aligned}
& \Pi_{12}^{(\{12\},\{34\})}=\frac{\left(6 d \bar{\theta}+10 d^{\frac{1}{a}}-17(2 d)^{\frac{1}{a}}+6(3 d)^{\frac{1}{a}}\right)\left(d \bar{\theta}-2(2 d)^{\frac{1}{a}}+(3 d)^{\frac{1}{a}}\right)}{100 d}, \\
& \Pi_{34}^{(\{12\},\{34\})}=\frac{61 d^{2} \bar{\theta}^{2}+36 d \theta(2 d)^{\frac{1}{a}}+2 d \theta(3 d)^{\frac{1}{a}}-50 d \theta(4 d)^{\frac{1}{a}}+9(2 d)^{\frac{2}{a}}}{100 d}+ \\
& \frac{41(3 d)^{\frac{2}{a}}+25(4 d)^{\frac{2}{a}}-24(2 d)^{\frac{1}{a}}(3 d)^{\frac{1}{a}}-50(3 d)^{\frac{1}{a}}(4 d)^{\frac{1}{a}}}{100 d},
\end{aligned}
$$

for $C=(\{123\},\{4\})$,

$$
\begin{aligned}
& \Pi_{123}^{(\{123\},\{4\})}=\frac{\left(8 d \bar{\theta}+13(2 d)^{\frac{1}{a}}-22(3 d)^{\frac{1}{a}}+8(4 d)^{\frac{1}{a}}\right)\left(3 d \bar{\theta}-5(3 d)^{\frac{1}{a}}+3(4 d)^{\frac{1}{a}}\right)}{338 d}, \\
& \Pi_{4}^{(\{123\},\{4\})}=\frac{\left(8 d \bar{\theta}+4(3 d)^{\frac{1}{a}}-5(4 d)^{\frac{1}{a}}\right)^{2}}{169 d},
\end{aligned}
$$

for $C=(\{1\},\{2\},\{34\})$,

$$
\begin{aligned}
& \Pi_{1}^{(\{1\},\{2\},\{34\})}=\frac{\left(d \bar{\theta}-12 d^{\frac{1}{a}}+4(2 d)^{\frac{1}{a}}+(3 d)^{\frac{1}{a}}\right)^{2}}{338 d}, \\
& \Pi_{2}^{(\{1\},\{2\},\{34\})}=\frac{2\left(2 d \bar{\theta}+2 d^{\frac{1}{a}}-5(2 d)^{\frac{1}{a}}+2(3 d)^{\frac{1}{a}}\right)^{2}}{169 d}, \\
& \Pi_{34}^{(\{1\},\{2\},\{34\})}=\frac{60 d \bar{\theta} d{ }^{\frac{1}{a}}+394 d^{2} \bar{\theta}^{2}+4 d^{\frac{2}{a}}+240 d \bar{\theta}(2 d)^{\frac{1}{a}}+8 d \bar{\theta}(3 d)^{\frac{1}{a}}-338 d \bar{\theta}(4 d)^{\frac{1}{a}}+64(2 d)^{\frac{2}{a}}+290(3 d)^{\frac{2}{a}}}{676 d}, \\
& +\frac{169(4 d)^{\frac{2}{a}}+32 d^{\frac{1}{a}}(2 d)^{\frac{1}{a}}-44 d^{\frac{1}{a}}(3 d)^{\frac{1}{a}}-176(2 d)^{\frac{1}{a}}(3 d)^{\frac{1}{a}}-338(3 d)^{\frac{1}{a}}(4 d)^{\frac{1}{a}}}{676 d},
\end{aligned}
$$

for $C=(\{1\},\{234\})$,

$$
\begin{aligned}
& \Pi_{1}^{(\{1\},\{234\})}=\frac{2\left(d \theta-3 d^{\frac{1}{a}}+(2 d)^{\frac{1}{a}}\right)^{2}}{49 d}, \\
& \Pi_{234}^{(\{1\},\{234\})}=\frac{64 d \theta d^{\frac{1}{a}}+162 d^{2} \theta^{2}+16 d^{\frac{2}{a}}+2 d \theta(2 d)^{\frac{1}{a}}-98 d \theta(4 d)^{\frac{1}{a}}+85(2 d)^{\frac{2}{a}}}{196 d}+ \\
& \frac{98(3 d)^{\frac{2}{a}}+49(4 d)^{\frac{2}{a}}-48 d^{\frac{1}{a}}(2 d)^{\frac{1}{a}}-98(2 d)^{\frac{1}{a}}(3 d)^{\frac{1}{a}}-98(3 d)^{\frac{1}{a}}(4 d)^{\frac{1}{a}}}{196 d},
\end{aligned}
$$

and, finally, for $C=(\{1\},\{23\},\{4\})$, 


$$
\begin{aligned}
& \Pi_{1}^{(\{1\},\{23\},\{4\})}=\frac{2\left(2 d \bar{\theta}-33 d^{\frac{1}{a}}+10(2 d)^{\frac{1}{a}}+(3 d)^{\frac{1}{a}}+2(4 d)^{\frac{1}{a}}\right)^{2}}{5329 d}, \\
& \Pi_{23}^{(\{1\},\{23\},\{4\})}=\frac{2190 d \theta d^{\frac{1}{a}}+169 d^{2} \theta^{2}+148 d^{\frac{2}{a}}+11 d \theta(2 d)^{\frac{1}{a}}-634 d \theta(3 d)^{\frac{1}{a}}+338 d \theta(4 d)^{\frac{1}{a}}}{5329 d} \\
& +\frac{1159(2 d)^{\frac{2}{a}}+973(3 d)^{\frac{2}{a}}+169(4 d)^{\frac{2}{a}}-656 d^{\frac{1}{a}}(2 d)^{\frac{1}{a}}}{5329 d} \\
& +\frac{222 d^{\frac{1}{a}}(3 d)^{\frac{1}{a}}+190 d^{\frac{1}{a}}(4 d)^{\frac{1}{a}}-1345(2 d)^{\frac{1}{a}}(3 d)^{\frac{1}{a}}+11(2 d)^{\frac{1}{a}}(4 d)^{\frac{1}{a}}-634(3 d)^{\frac{1}{a}}(4 d)^{\frac{1}{a}}}{5329 d} \\
& \Pi_{4}^{(\{1\},\{23\},\{4\})}=\frac{\left(44 d \bar{\theta}+4 d^{\frac{1}{a}}+(2 d)^{\frac{1}{a}}+22(3 d)^{\frac{1}{a}}-29(4 d)^{\frac{1}{a}}\right)^{2}}{5329 d} .
\end{aligned}
$$

Numerical simulations show that when costs increase less than proportionally with quality $(a>1)$, the grand coalition payoff (solid red line) exceeds the sum of firms' profits in all alternative coalition structures (Figure 5). The most profitable alternatives appear to be $C=(\{12\},\{34\})$ for relatively low values of $a$ (solid green line) and $C=(\{1\},\{234\})$ for relatively high values of $a$ (solid blue line).

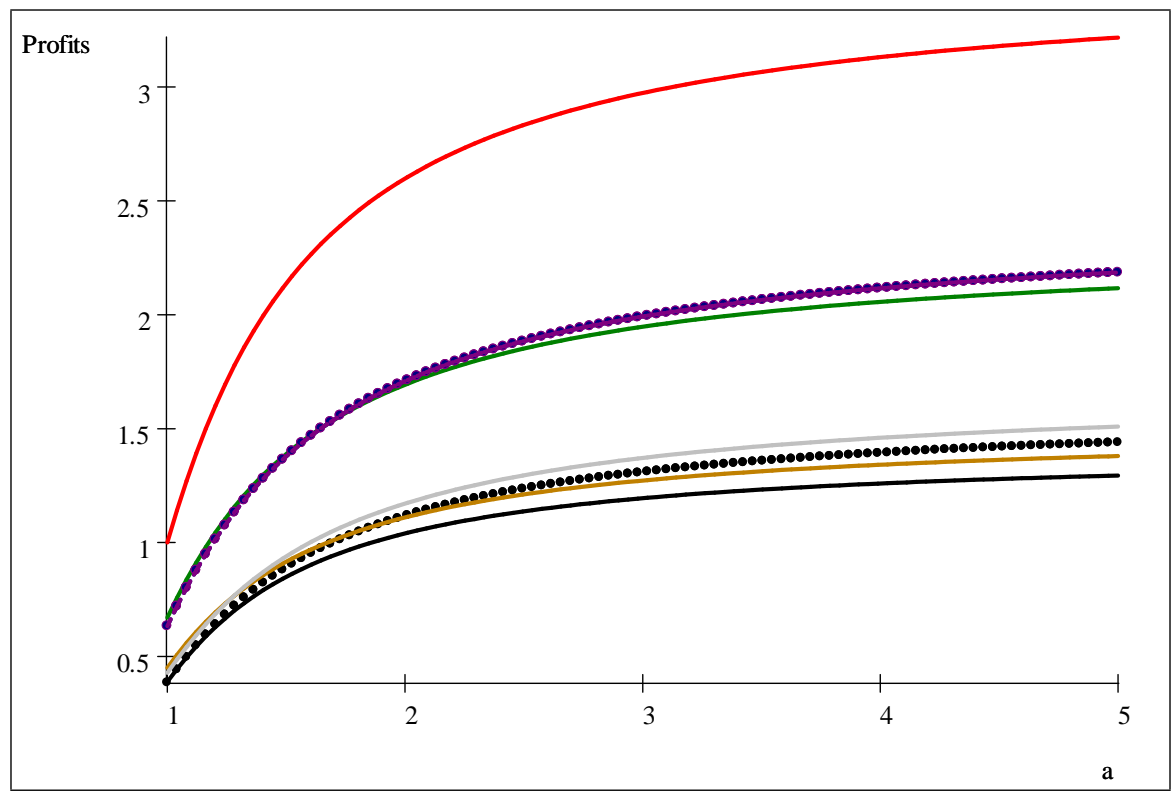

Figure 5 - Sum of all firms' profits in the different coalition structures: (i) grand coalition (red line); (ii) all firms as singletons (black dotted line); (iii) coalition structures with bottom cartels, $C=(\{12\},\{3\},\{4\})$ and $C=(\{123\},\{4\})$ (black and and brown continuous lines); (iv) twocartel coalition structure $C=(\{12\},\{34\})$ (green continuous line); coalition structures with top cartels $C=(\{1\},\{234\})$ and $C=(\{1\},\{2\},\{34\})$ (blue and purple circled lines); (v) coalition structure with an intermediate cartel $C=(\{1\},\{23\},\{4\})$ (grey line); $\bar{\theta}=2, d=1, a \in[1,5]$.

Finally, when costs increase more than proportionally with quality $(0<a<1)$, all variants remain on sale and corresponding payoffs can be computed in a similar fashion. Figure 6 below depicts the results of the numerical simulations. As before, the solid red line represents 
the grand coalition payoff, which is larger than the sum of firms 'profits in any other coalition structure.

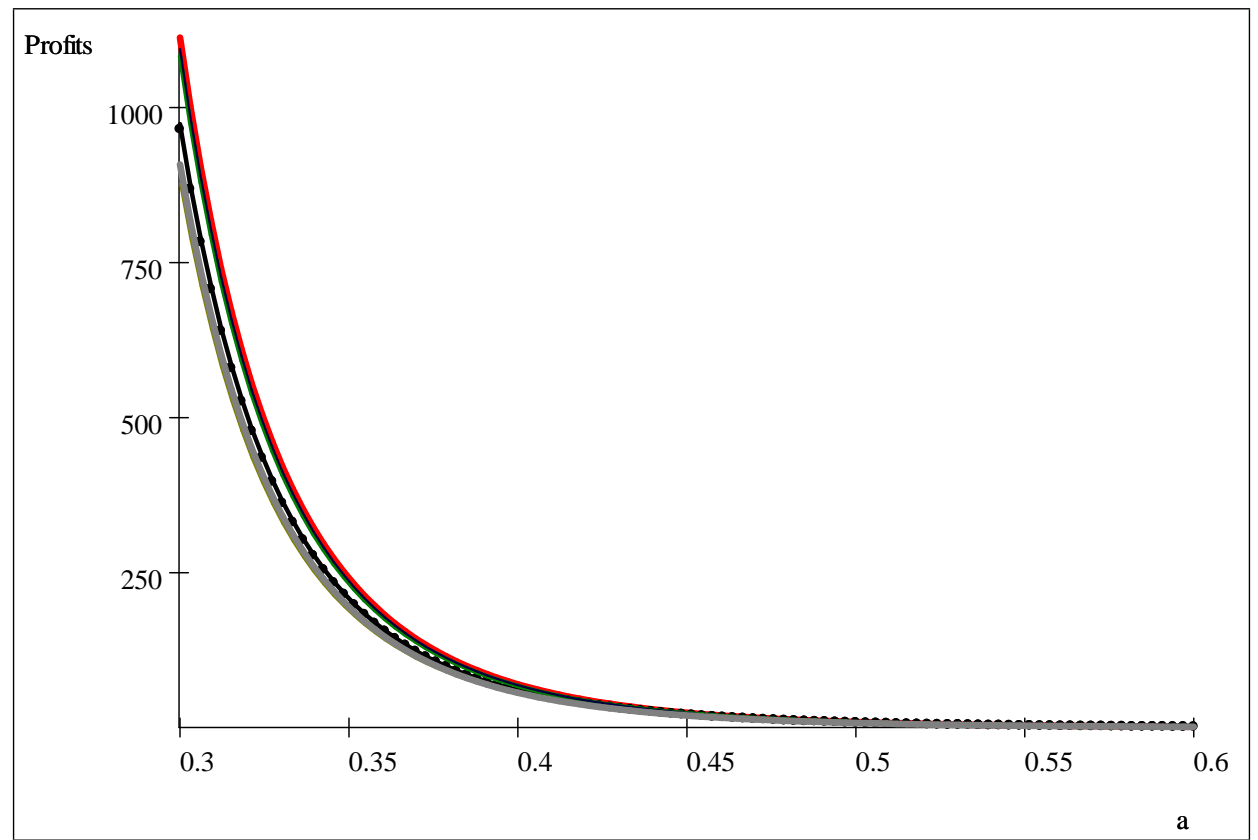

Figure 6 - Sum of all firms' profits in all coalition structures (same colours as in Figure $5 ; \bar{\theta}=2$, $d=1$ and $a \in[0.3,0.6])$.

In sum, our numerical simulations confirm the result of Proposition 7 when costs are more or less than proportionally increasing with quality. Also in this case, the only coalitionally stable coalition is the one comprising the entire industry.

\section{REFERENCES}

[1] Bonnet, C. and Z. Bouamra-Mechemache (2019), "Yogurt Cartel'Yogurt Cartel' of Private Label Providers in France: Impact on Prices and Welfare," TSE Working Papers 19-1012, Toulouse School of Economics.

[2] Bos, I. and M.A. Marini (2019), "Cartel Stability under Quality Differentiation," Economics Letters, 174(C),70-73.

[3] Bos, I. and J.E. Harrington Jr. (2010), "Endogenous Cartel Formation with Heterogeneous Firms", RAND Journal of Economics, 41(1), 92-117.

[4] Bos, I. (2009), "Incomplete Cartels and Antitrust Policy: Incidence and Detection," Ph.D. Dissertation, Thela Thesis no. 463, Tinbergen Institute, University of Amsterdam.

[5] Brod, A. and R. Shivakumar (1999), "Advantageous Semi-Collusion," Journal of Industrial Economics, 47(2), 221-230;

[6] Champsaur, P. and J-C. Rochet (1989), "Multiproduct Duopolists," Econometrica, 57(3), 533-557.

[7] Demange, G. (1994), "Intermediate Preferences and Stable Coalition Structures," Journal of Mathematical Economics, 23, 45-58.

[8] Demange, G. (2017), "The Stability of Group Formation,", Revue D'Economie Politique, 217(4), 495516.

[9] Drèze, J. H. and J. Greenberg, (1980). "Hedonic Coalitions: Optimality and Stability," Econometrica, 48(4), 987-1003.

[10] Donsimoni, M-P. (1985), "Stable Heterogeneous Cartels," International Journal of Industrial Organization, 3(4), 451-467.

[11] Ecchia, G. and L. Lambertini (1997), "Minimum Quality Standards and Collusion," Journal of Industrial Economics, 45(1), 101-113. 
[12] Farrell, J. and S. Scotchtmer (1988), "Partnership,", The Quarterly Journal of Economics, 103, 279-297.

[13] Fershtman, C. and N. Gandal (1994), "Disadvantageous Semicollusion," International Journal of Industrial Organization, 12(2), 141-154.

[14] Friedman, J.W. (1991), Game Theory with Applications to Economics. Oxford University Press, Oxford.

[15] Gabszewicz, J.J. M.A. Marini and O. Tarola (2019), "Endogenous Mergers in Markets with Vertically Differentiated Products," B.E. Journal of Theoretical Economics, 19(1), 1-22.

[16] Gabszewicz J.J., M.A. Marini and O. Tarola (2017), "Vertical Differentiation and Collusion: Pruning or Proliferation?," Research in Economics, 71(1), 129-139.

[17] Gabszewicz J.J., M.A. Marini and O. Tarola (2016), "Core Existence in Vertically Differentiated Markets," Economics Letters, 149, 28-32.

[18] Gabszewicz, J.J., A. Shaked, J. Sutton, J-F. Thisse, (1986), "Segmenting the Market: the Monopolist's Optimal Product Mix," Journal of Economic Theory, 39(2), 273-289.

[19] Gabszewicz, J.J. and J-F. Thisse (1979), "Price competition, Quality and Income Disparities," Journal of Economic Theory, 20(3), 340-359.

[20] Greenberg, J. and S. Weber, "Stable Coalition Structures with Unidimensional Set of Alternatives,", Journal of Economic Theory, 60, 62-82.

[21] Häckner, J. (1994), "Collusive pricing in markets for vertically differentiated products," International Journal of Industrial Organization, 12(2), 155-177.

[22] Hart, S. and M. Kurz (1983), "Endogenous Formation of Coalitions," Econometrica, 51(4), 1047-1064.

[23] Marini, M. A. (2009), "Games of Coalition \& Network Formation: a Survey," in Naizmada A.K. et al. (eds.). Networks, Topology and Dynamics. Lectures Notes in Economics 85 Mathematical Systems, 613, 67-93, Berlin Heidelberg, Springer-Verlag.

[24] Marini, M.A. (2018), "Collusive Agreements in Vertically Differentiated Markets," in Handbook of Game Theory and Industrial Organization, Volume 2: Applications, L.C. Corchon and M.A. Marini (eds.), Edward Elgar, Cheltenham, UK, Northampton, MA, USA.

[25] Merker, T. (2019), "The Effect of Product Differentiation on Cartel Stability," Discussion Paper, University of Oslo.

[26] Mussa, M. and S. Rosen (1978), "Monopoly and Product Quality," Journal of Economic Theory, 18(2), 301-317.

[27] Paha, J. (2010), "Endogenous Cartel Formation with Heterogeneous Firms and Differentiated Products," Discussion Paper, Justus-Liebig-University Giessen.

[28] Shaked, A. and J. Sutton (1982), "Relaxing Price Competition Through Product Differentiation," Review of Economic Studies, 49(1), 3-13.

[29] Steen, F. and L. Sørgard (2009), "Semicollusion," Foundations and Trends in Microeconomics, 5(3), 153-228.

[30] Sullivan, C.J. (2017), "Three Essays on Product Collusion," Ph.D. Dissertation, University of Michigan.

[31] Symeonidis, G. (1999), "Cartel stability in advertising-intensive and R\&D-intensive industries," Economics Letters, 62, 121-129.

[32] Vives, X. (2000). Oligopoly Pricing. Old Ideas and New Tools. MIT Press, Cambridge, Massachusetts.

[33] Von Neumann, J., and Morgenstern, O., (1944). Theory of Games and Economic Behavior. Princeton: Princeton University Press. 